\title{
RADIOLOGICAL SCOPING SURVEY OF THE SCOTIA DEPOT SCOTIA, NEW YORK
}

\section{E. N. Bailey}

\section{Prepared for the}

Defense National Stockpile Center of the

Defense Logistics Agency

\section{O R $\mathrm{I}$ I E}

Oak Ridge Institute for Science and Education

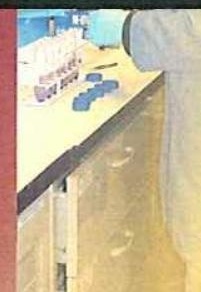

Approved for public release; further dissemination unlimited. 
The Oak Ridge Institute for Science and Education (ORISE) is a U.S. Department of Energy facility focusing on scientific initiatives to research health risks from occupational hazards, assess environmental cleanup, respond to radiation medical emergencies, support national security and emergency preparedness, and educate the next generation of scientists. ORISE is managed by Oak Ridge Associated Universities. Established in 1946, ORAU is a consortium of 96 colleges and universities.

\section{NOTICES}

The opinions expressed herein do not necessarily reflect the opinions of the sponsoring institutions of Oak Ridge Associated Universities.

This report was prepared as an account of work sponsored by the United States Government. Neither the United States Government nor the U.S. Department of Energy, nor any of their employees, makes any warranty, expressed or implied, or assumes any legal liability or responsibility for the accuracy, completeness, or usefulness of any information, apparatus, product, or process disclosed, or represents that its use would not infringe on privately owned rights. Reference herein to any specific commercial product, process, or service by trade name, mark, manufacturer, or otherwise, does not necessarily constitute or imply its endorsement or recommendation, or favor by the U.S. Government or any agency thereof. The views and opinions of authors expressed herein do not necessarily state or reflect those of the U.S. Government or any agency thereof. 


\title{
RADIOLOGICAL SCOPING SURVEY OF THE SCOTIA DEPOT SCOTIA, NEW YORK
}

\author{
Prepared by \\ E. N. Bailey \\ Oak Ridge Institute for Science and Education \\ Oak Ridge, Tennessee 37831-0117 \\ Prepared for the \\ Defense National Stockpile Center \\ of the \\ Defense Logistics Agency
}

FINAL REPORT

FEBRUARY 2008

This report is based on work performed under contract number DE-AC05-06OR23100 with the U.S. Department of Energy. 


\section{RADIOLOGICAL SCOPING SURVEY OF THE SCO'TIA DEPO'T SCO'TIA, NEW YORK}

Prepared by: $\frac{\text { Crika Y. Balle }}{\text { E. N. Bailey, Project Leader }}$
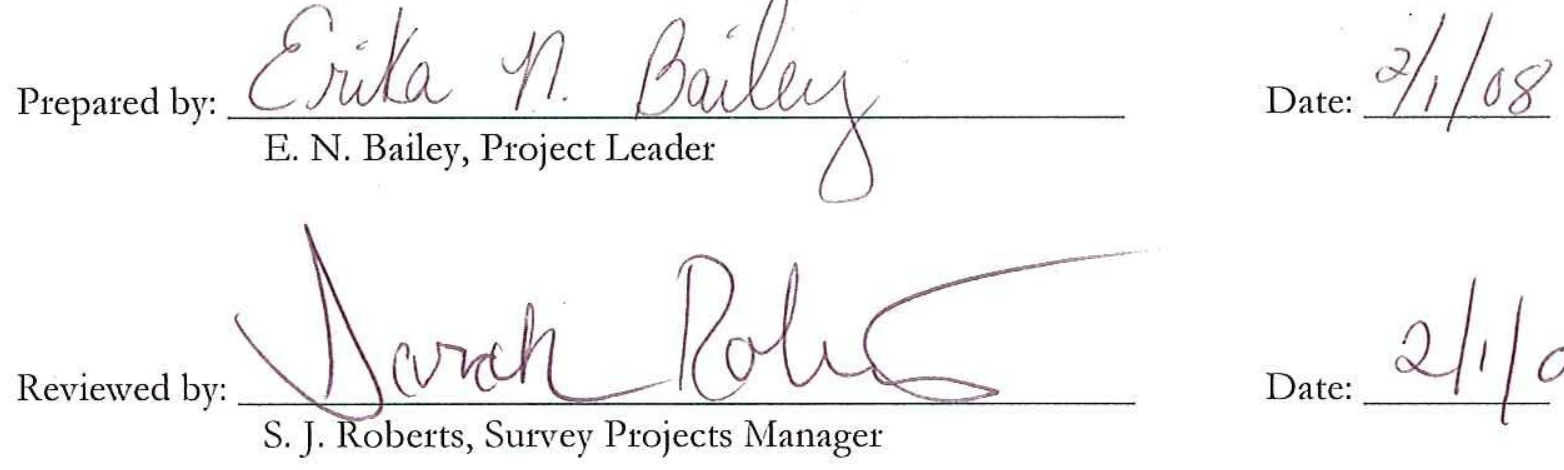

Date: $2 / 1 / 08$

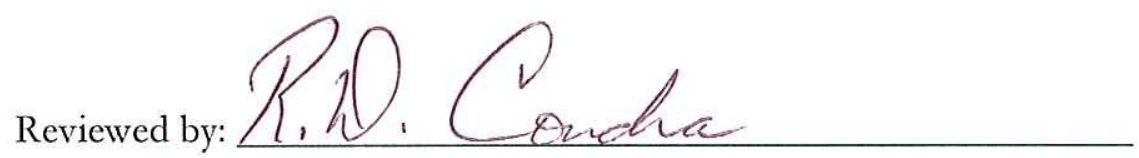

R. D. Condra, Laboratory Manager

Date: $34 / 08$

Reviewed by: $\operatorname{lamn} 7$ Parpe

A. T. Payne, Quality Manager

Date: $2 / 1 / 08$ 


\section{ACKNOWLEDGMENTS}

The author would like to acknowledge the significant contributions of the following staff members:

\section{PROJECT STAFF}

T. J. Vitkus

\section{FIELD STAFF}

T. D. Herrera

\section{LABORATORY STAFF}

R. D. Condra

W. P. Ivey

J. S. Cox

W. F. Smith

\section{CLERICAL STAFF}

R. M. Fink

K. M. Moore

A. Ramsey

\section{ILLUSTRATOR}

T. L. Brown

J. A. Viars 
$\underline{\text { PAGE }}$

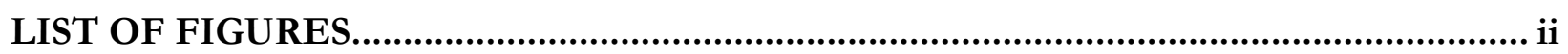

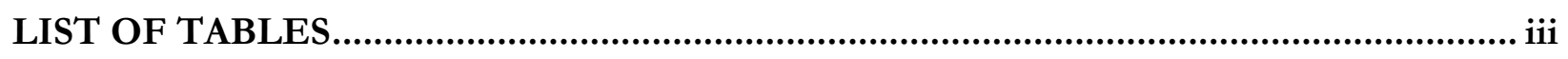

ABBREVIATIONS AND ACRONYMS …………...............................................................iv

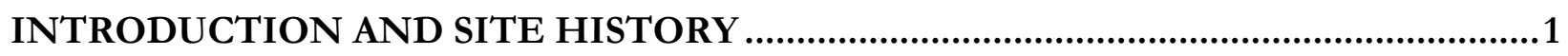

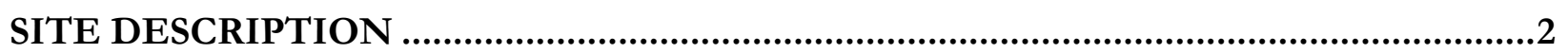

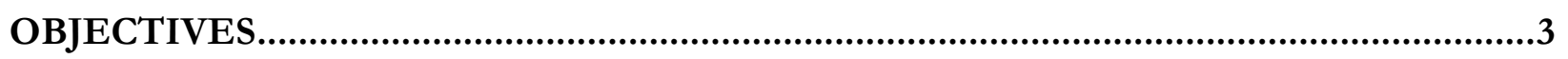

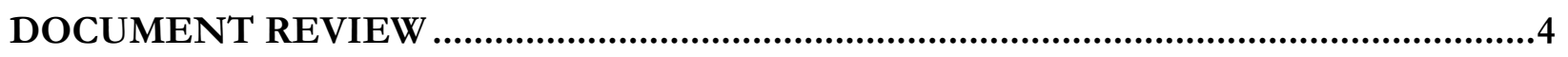

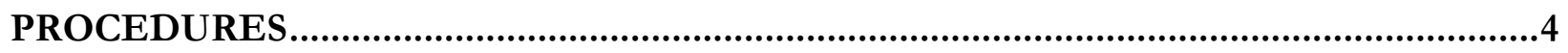

Building Survey Procedures: Class 1 ............................................................................................

Building Survey Procedures: Class 2 ..................................................................................................

Building Survey Procedures: Class 3 ...................................................................................................

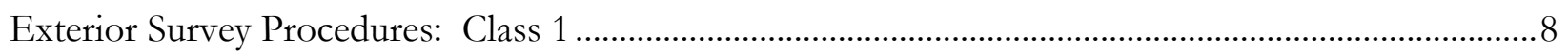

Exterior Survey Procedures: Class 2 ………………………………………………………...

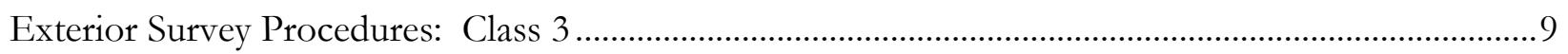

SAMPLE ANALYSIS AND DATA INTERPRETATION.............................................

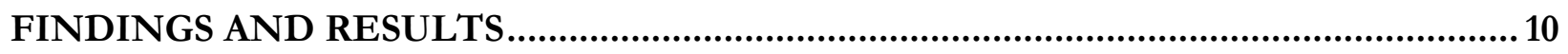

Building Surface Scans ................................................................................................................10

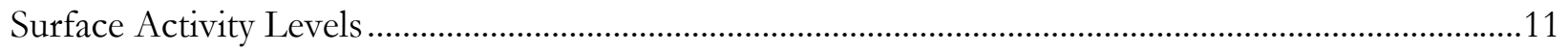

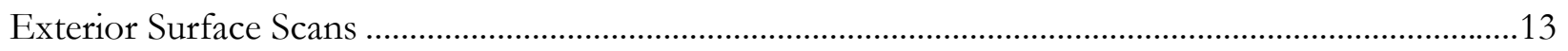

Radionuclide Concentrations in Soil Samples .............................................................................13

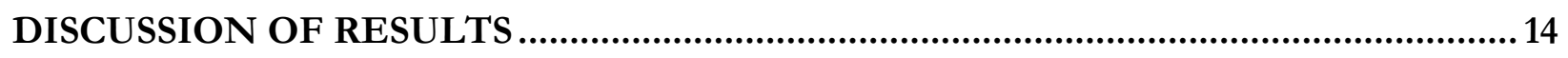

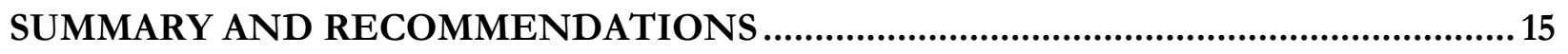

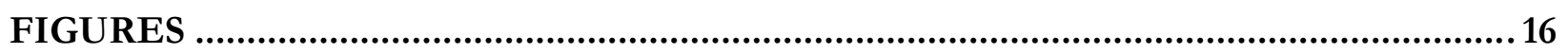

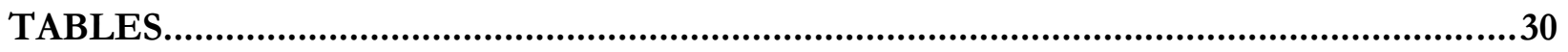

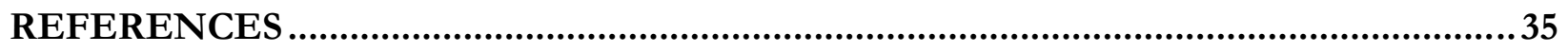

Appendices:

Appendix A: Major Instrumentation

Appendix B: Survey and Analytical Procedures 


\section{LIST OF FIGURES}

$\underline{\text { PAGE }}$

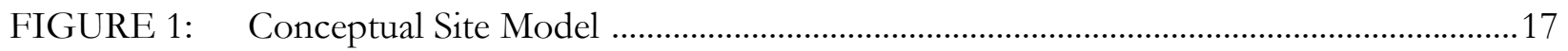

FIGURE 2: $\quad$ Building 12, Garage - Direct Measurement and Sample Locations .............................18

FIGURE 3: $\quad$ Building 14 - Direct Measurement and Sample Locations .........................................19

FIGURE 4: Building 505, Sections 1 \& 2 - Direct Measurement and Sample Locations .............20

FIGURE 5: Building 505, Sections 3 \& 4 - Direct Measurement and Sample Locations .............21

FIGURE 6: Building 506, Sections 1 \& 2 - Direct Measurement and Sample Locations .............22

FIGURE 7: Building 506, Sections 3 \& 4 - Direct Measurement and Sample Locations .............23

FIGURE 8: Building 22 - Direct Measurement and Sample Locations ...........................................24

FIGURE 9: $\quad$ Building 23 - Direct Measurement and Sample Locations .........................................25

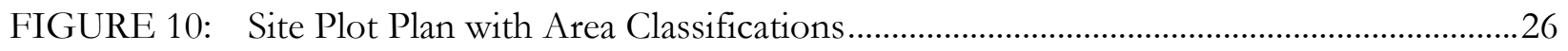

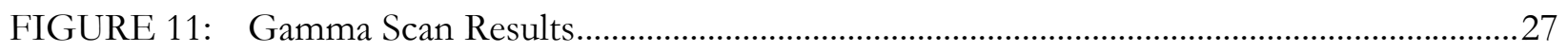

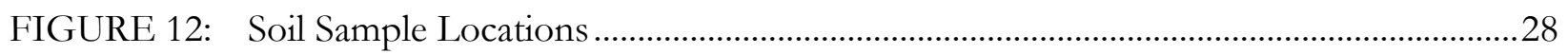

FIGURE 13: Cumulative Frequency Distribution...........................................................................29 


\section{LIST OF TABLES}

$\underline{\text { PAGE }}$

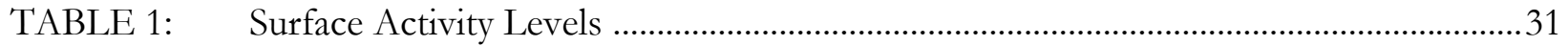

TABLE 2: $\quad$ Radionuclide Concentrations in Soil Samples .................................................................. 34 


\section{ABBREVIATIONS AND ACRONYMS}

\begin{tabular}{|c|c|}
\hline$\varepsilon_{\mathrm{i}}$ & instrument efficiency \\
\hline$\varepsilon_{\mathrm{s}}$ & surface efficiency \\
\hline$\varepsilon_{\text {total }}$ & total efficiency \\
\hline$b_{i}$ & number of background counts in the interval \\
\hline $\mathrm{BKG}$ & background \\
\hline $\mathrm{cm}$ & centimeter \\
\hline $\mathrm{cm}^{2}$ & square centimeter \\
\hline cpm & counts per minute \\
\hline d' & index of sensitivity \\
\hline DCGL & derived concentration guideline level \\
\hline DLA & Defense Logistics Agency \\
\hline DNSC & Defense National Stockpile Center \\
\hline DOE & U.S. Department of Energy \\
\hline $\mathrm{dpm} / 100 \mathrm{~cm}^{2}$ & disintegrations per minute per 100 square centimeters \\
\hline EML & Environmental Measurements Laboratory \\
\hline GPS & global positioning system \\
\hline GSA & General Services Administration \\
\hline HSA & Historical Site Assessment \\
\hline IEAV & Independent Environmental Assessment and Verification \\
\hline ITP & Intercomparison Testing Program \\
\hline JHA & job hazard analyses \\
\hline MAPEP & Mixed Analyte Performance Evaluation Program \\
\hline MARSSIM & Multi-Agency Radiation Survey and Site Investigation Manual \\
\hline MDC & minimum detectable concentration \\
\hline MDCR & minimum detectable count rate \\
\hline $\mathrm{MeV}$ & million electron volts \\
\hline $\mathrm{m}$ & meters \\
\hline $\mathrm{m}^{2}$ & square meter \\
\hline $\mathrm{mg} / \mathrm{cm}^{2}$ & milligram per square centimeter \\
\hline $\min$ & minute \\
\hline $\mathrm{mm}$ & millimeter \\
\hline $\mathrm{NaI}$ & sodium iodide \\
\hline NIST & National Institute of Standards and Technology \\
\hline NRC & U.S. Nuclear Regulatory Commission \\
\hline NRIP & NIST Radiochemistry Intercomparison Program \\
\hline ORISE & Oak Ridge Institute for Science and Education \\
\hline $\mathrm{pCi} / \mathrm{g}$ & picocuries per gram \\
\hline RESRAD & $\begin{array}{l}\text { RESisual RADioactivity - a computer code developed at } \\
\text { Argonne National Laboratory for the U.S. DOE }\end{array}$ \\
\hline $\mathrm{s}$ & second \\
\hline TAP & total absorption peak \\
\hline WHSE & warehouse \\
\hline
\end{tabular}




\section{RADIOLOGICAL SCOPING SURVEY OF THE SCOTIA DEPOT SCOTIA, NEW YORK}

\section{INTRODUCTION AND SITE HISTORY}

The Scotia Depot in Scotia, New York was originally constructed in 1943 to support navy operations and training. The land area for the Scotia Depot originally consisted of approximately 337 acres. In 1946, a National Stockpile program began with the goal of mitigating dependence on foreign sources of vital materials during times of national emergencies. Ownership for most of the site eventually transferred to the General Services Administration (GSA). The majority of the original depot has since been released for private industrial use. The remaining depot consists of approximately 14 acres and is owned by the GSA and operated by the Defense National Stockpile Center (DNSC).

The DNSC used the Scotia Depot to store strategic materials (bulk ores, minerals, and metals). The depot now consists of two warehouses (WHSE 505 and 506) and five support buildings. The warehouses have been used to store raw tungsten, columbium and tantalum ores. These particular ores contain varying concentrations of naturally-occurring radioactive material, primarily thorium and uranium. Over the history of the site, known storage containers have included burlap sacks, wooden kegs, wooden cases, and steel drums. Some materials were stored in open piles at various locations around the site. However, the materials stored in open piles within the current depot footprint were non-radioactive materials (e.g. zinc), and did not include tungsten, columbium or tantalum ores.

Originally, large portions of the tungsten ores were stored in burlap sacks before they were repackaged into drums. Drums of columbium tantalum ores received from other depots were stored outside in cordwood fashion before later being moved and stored inside in their original drums. As such, the materials identified as being potential sources of radioactive contamination at the Scotia Depot are columbium, tantalum and tungsten.

The columbium tantalum material contains thorium dioxide concentrations ranging from $<0.001$ to $0.104 \%$ by weight and uranium oxide concentrations ranging from 0.002 to $0.350 \%$ by weight (DNSC 1). The tungsten materials were initially assumed to not contain licensable concentrations of 
uranium and thorium until sampling of the drums was conducted by the DNSC from 1996 to 2003. This sampling revealed that some of the lots of tungsten contained total uranium and thorium above the threshold required for licensing of source material $(0.05 \%$ total $\mathrm{U}+$ Th by weight). The range of thorium dioxide was $0.044 \%$ to $0.096 \%$ and the range for uranium dioxide was $0.001 \%$ to $0.029 \%$ (DNSC 2). These materials contained radioactive material at concentrations that required them to be listed on the DNSC's Nuclear Regulatory Commission (NRC) source material license STC-133 that permits the storage of uranium and thorium. All licensable radioactive material has since been removed from the depot, and the license has been amended to conduct site cleanup activities (NRC 2007a). The Scotia Depot continues to store stockpiled ores, metals and minerals, such as ferrochrome and tungsten in non-licensable concentrations.

The DNSC of the Defense Logistics Agency (DLA) is now in the process of closing out many of its depots across the country and/or seeking to terminate its NRC license for those facilities. The initial phase of the license termination activities was initiated when the DNSC removed the remaining licensable source material from the site. In conjunction with this initial phase, at the request of the DLA, the Oak Ridge Institute for Science and Education (ORISE) performed a Historical Site Assessment (HSA) of the Scotia Depot in order to plan for future site investigations (ORISE 2007a). Additionally, ORISE was tasked with conducting scoping surveys of the site to validate the results of the HSA, to provide information for the complete site characterization survey and to determine the need for any eventual remediation activities. The scoping survey was conducted September 24 through 27, 2007.

\section{SITE DESCRIPTION}

The current Scotia Depot property consists of a 13.92 acre parcel of land just west of the village of Scotia, New York. The depot is surrounded on all sides by an industrial/commercial business park, which was formerly part of the 337 acre depot. Further to the east and west, the land use is mixed residential/commercial. Land use to the south of the depot is a mixture of commercial, residential, agricultural, and recreational. The Erie Canal/Mohawk River is about 2,000 feet south of the depot, and a large sand and gravel quarry is located to the north, beyond which the land use is residential. A security fence encloses the depot with 24-hour security personnel. 
The depot has seven buildings, including two warehouses and five support buildings, mostly in good to excellent condition. The two warehouses (WHSE 505 and 506) are currently used to store raw materials. Both warehouses are identical in design. The buildings are constructed from steel sided cinderblock walls and wooden trusses, with a foam-covered gypsum board roof. Each warehouse is approximately 200 feet by 600 feet, divided into 4 sections by cinderblock firewalls extending through the roof. For naming convention, the sections within each warehouse are numbered as Sections 1, 2, 3 and 4 from west to east. The interior of each warehouse is further divided into 300 bays, consisting of 10 east-west rows designated alphabetically as A through J, and 30 north-south columns designated numerically as 1 through 30. Sections 1 and 4 each have eight columns of bays, while Sections 2 and 3 each have seven columns of bays. The concrete floors are cracked in many places. Currently, approximately $60 \%$ of the available $120,000 \mathrm{ft}^{2}$ of indoor storage space in each warehouse is occupied.

Warehouses 505 and 506 were and are currently used to store tungsten ore. Material handling events such as repackaging and sampling have taken place in both warehouses over the years. Site personnel removed all ores stored in Bays H-I-J/20-21-22 in WHSE 505 prior to ORISE survey activities. This area of the warehouse exhibited the greatest contamination concern due to a tungsten repackaging event that was performed around 1980. At the time of repackaging, the material was not considered licensable but an employee recalled that significant amounts of tungsten dust accumulated in the area.

\section{OBJECTIVES}

The objectives of the radiological scoping survey were to collect adequate field data for use in evaluating the radiological condition of Scotia Depot land areas, warehouses, and support buildings. The data generated were used to validate the results of the HSA regarding classification of areas by radiological contamination potential; validate the radiological contaminants of concern (thorium and uranium, or thorium only); determine whether contamination present warrants further evaluation, and if required support site-specific derived concentration guideline level (DCGL) modeling; provide input information for the development of a complete site characterization plan; and provide preliminary estimates of the level of effort for decontamination. 


\section{DOCUMENT REVIEW}

ORISE reviewed the HSA during the preparation of the scoping survey plan that was utilized at the site.

\section{PROCEDURES}

A survey team from ORISE visited the Scotia Depot and performed visual inspections, as well as measurement and sampling activities. Scoping survey activities were conducted in accordance with a site-specific survey plan, the ORISE/IEAV Survey Procedures Manual and Quality Assurance Program (ORISE 2007d and 2007b and ORAU 2007). Because the warehouses continue to be used for storage, the accessible area available for survey was in some cases less than the proposed scan percentages discussed below. Therefore, the proposed survey/scan coverage was modified accordingly.

ORISE divided the Scotia Depot site into three categories, based on contamination potential, as either Class 1, 2, or 3 in accordance with the Multi-Agency Radiation Survey and Site Investigation Manual (MARSSIM) (NRC 2000). A description of each is as follows:

Class 1: $\quad$ Buildings or land areas that have a significant potential for radioactive contamination (based on site operating history) or known contamination (based on previous radiological surveys) that exceeds the expected $\mathrm{DCGL}_{\mathbb{W}}$.

Class 2: $\quad$ Buildings or land areas, often contiguous to Class 1 areas, that have a potential for radioactive contamination but at levels less than the expected $\mathrm{DCGL}_{\mathbb{W}}$.

Class 3: $\quad$ Remaining buildings and land areas that are expected to contain little or no residual contamination based on site operating history or previous radiological surveys.

Figures 1 and 10 illustrate the site area classifications. 


\section{Building Survey Procedures: Class 1}

The following survey procedures were applicable to Class 1 buildings where the potential existed for contamination based on operating history. Specifically, this classification applied to WHSE 505, WHSE 506, the west end (garage) of Building 12, and Building 14.

\section{$\underline{\text { Reference Grid }}$}

ORISE referenced survey information to the building's alphanumeric bay designation and specific $\mathrm{X}, \mathrm{Y}$ coordinates from the southwest corner of the respective bay or room. Information was plotted on site drawings. Measurements and samples collected on upper surfaces were referenced to the floor and/or lower wall coordinates or to prominent building features.

\section{$\underline{\text { Surface Scans }}$}

The concrete floors in Warehouses 505 and 506 were scanned for alpha-only radiation due to the elevated ambient background gamma radiation levels that are the result of continued tungsten storage and vary significantly from location to location. The observed ambient levels varied dependent upon the proximity to stored tungsten and the varying thorium and uranium concentrations within the different lots. The concrete floors of the remaining Class 1 building areas were scanned for alpha plus beta and gamma radiation. Lower and upper surfaces were scanned for alpha-only, beta-only and in a few instances beta-gamma radiation (using a smaller GM probe). Because the objective of the scoping survey was to validate the results of the HSA and obtain data of the general radiation levels for future planning, the scan density of surfaces was highly variable.

The overall scan coverage of the two warehouses was minimal due to their sheer size and current material storage. Scans were focused in specific bays of concern, transportation pathways, and areas in which repackaging events and/or spills occurred. However, the minimum surface scan coverage of the accessible surfaces within the areas of concern was $25 \%$, with several areas being scanned at a much greater frequency. Because of difficulties encountered with accessing upper surfaces, areas within the buildings were judgmentally selected for survey. An area of at least $1 \mathrm{~m}^{2}$ was scanned within each of these selected areas. 
In the remaining Class 1 building areas the minimum surface scan coverage of the accessible surfaces was also $25 \%$ with the exception of upper surfaces. Due to time constraints and professional judgment, ORISE did not perform surface scans above 2 meters. The floor scan coverage was much higher. No scans were performed in the refurbished site office area of Building 12. Scans of accessible lower surfaces concentrated on surfaces where material may have accumulated. The total area covered was dependent upon results as the survey progressed. Particular attention was given to cracks and joints in the floor and walls, ledges, and other horizontal surfaces where material may have accumulated. Scans were performed using sodium iodide (NaI) scintillation detectors for direct gamma radiation and gas proportional detectors for direct alpha-only, alpha plus beta, and beta-only radiation, coupled to ratemeters or ratemeter-scalers with audible indicators. Locations of elevated direct radiation were marked for further investigation. Identification of areas requiring additional investigation was based on instrument count rates that were audibly distinguishable above background.

\section{Surface Activity Measurements}

Construction material-specific backgrounds were determined in areas of similar construction but without a history of radioactive material use. These construction material-specific measurements were used to correct direct measurements for background contributions. Direct measurements to quantify total alpha and beta activity levels were performed at judgmental locations and at locations with elevated radiation levels identified by surface scans. Random locations were not generated for the scoping survey due to the amount of materials and/or equipment that remained in each building and the likelihood that many of the random locations would fall in areas that were inaccessible. To account for the ambient gamma background, unshielded and shielded measurements were performed at each direct measurement location. The number of direct measurements on the floor and lower surfaces varied within each Class 1 area. On upper surfaces, direct measurements were performed within the areas that were selected for judgmental scanning. Direct measurements were made using gas proportional detectors coupled to ratemeter-scalers. A smear sample, to determine removable gross alpha and gross beta activity levels, was collected from each direct measurement location. Measurement locations for Class 1 areas are shown on Figures 2 through 7. 


\section{Building Survey Procedures: Class 2}

There were no Class 2 building areas identified during the HSA.

\section{Building Survey Procedures: Class 3}

The following procedures were used for buildings designated as Class 3. Specifically this classification applied to Building 11, Building 12 (the west end (garage) was Class 1), Building 22, and Building 23. However, due to time constraints and professional judgment, ORISE did not perform scans in Building 11 (the security guardhouse which was constructed in 2003) and the refurbished site office area of Building 12.

\section{$\underline{\text { Reference Grid }}$}

ORISE referenced survey information to the building's X, Y coordinates from the southwest corner of the respective room. Information was plotted on site drawings.

\section{$\underline{\text { Surface Scans }}$}

The concrete floors were scanned for alpha plus beta and gamma radiation. Lower surfaces were scanned for alpha-only and beta-only radiation. The minimum surface scan coverage was $25 \%$ with the exception of upper surfaces. Because of time constraints ORISE did not perform surface scans above 2 meters. The floor scan coverage was much higher. Scans of accessible lower surfaces concentrated on surfaces where material may have accumulated. The total area covered was dependent upon results as the survey progressed. Particular attention was given to cracks and joints in the floor and walls, ledges, and other horizontal surfaces where material may have accumulated. Scans were performed using $\mathrm{NaI}$ scintillation detectors for direct gamma radiation and gas proportional detectors for direct alpha plus beta, alpha-only, and beta-only radiation, coupled to ratemeters or ratemeter-scalers with audible indicators. 


\section{Surface Activity Measurements}

Direct measurements to quantify total alpha and beta activity levels were performed at judgmental locations and at locations with elevated radiation levels identified by surface scans. Random locations were not generated for the scoping survey due to the amount of materials and/or equipment that remained in each building and the likelihood that many of the random locations would fall in areas that were inaccessible. To be consistent with the procedures used for Class 1 areas, unshielded and shielded measurements were performed at each direct measurement location. The previously discussed construction material-specific background measurements were used to correct measurements for background contributions. The number of direct measurements on the floor and lower surfaces varied within each Class 3 area. Because of time constraints ORISE did not perform direct measurements above 2 meters. Direct measurements were made using gas proportional detectors coupled to ratemeter-scalers. A smear sample, to determine removable gross alpha and gross beta activity levels, was collected from each direct measurement location. Measurement locations for Class 3 areas are shown on Figures 8 and 9.

\section{Exterior Survey Procedures: Class 1}

There were no Class 1 land areas identified during the HSA.

\section{Exterior Survey Procedures: Class 2}

The following survey procedures were applicable to accessible, exterior land areas identified as Class 2 (Figure 10). Specifically, this included the land area surrounding Warehouses 505 and 506 including roadways and former railroad lines.

\section{$\underline{\text { Reference System }}$}

A site grid system was not established. Measurement and sampling locations were referenced using a global positioning system (GPS) and/or referenced to prominent site features. 


\section{$\underline{\text { Surface Scans }}$}

Surface scans for direct gamma radiation were performed over approximately $100 \%$ of accessible surfaces. A large ferrochrome storage pile remains in between the eastern ends of the warehouses. Gamma scans were performed using $\mathrm{NaI}$ scintillation detectors coupled to ratemeters with audible indicators coupled to a GPS system that logged the real time gamma count rate with the corresponding GPS position. Locations of elevated direct gamma radiation were marked for further investigation.

\section{Soil Sampling}

Surface (0 to $15 \mathrm{~cm}$ ) soil samples were collected from judgmental locations identified during surface scans where direct gamma radiation was distinguishable above background. Specific sampling locations corresponded to the area of maximum direct radiation within the discrete areas above background-e.g. perimeter of a given building. Five samples were collected from Class 2 land areas (Figure 12).

\section{Exterior Survey Procedures: Class 3}

The remaining portion of the land area that was not designated as Class 2 was classified as Class 3 (as illustrated in Figure 10). Gamma surface scans for direct gamma radiation were performed over approximately $100 \%$ of accessible surfaces. Scans were performed using $\mathrm{NaI}$ scintillation detectors coupled to ratemeters with audible indicators coupled to the GPS system described above. Locations of elevated direct gamma radiation were marked for further investigation.

Sample locations and the number of samples ultimately collected were determined as the survey progressed and in a manner similar to the process described above for Class 2 areas. Locations of direct gamma radiation distinguishable from background in the Class 3 areas were judgmentally selected for surface soil sampling. Three soil samples were collected. This number includes one sample (S004) that was collected from what appeared to be a non-impacted area of the site to use as a preliminary background reference sample. Refer to Figures 11 and 12 for surface gamma scan results and soil sampling locations. 


\section{SAMPLE ANALYSIS AND DATA INTERPRETATION}

Samples and data were returned to ORISE's laboratory in Oak Ridge, Tennessee for analysis and interpretation. Samples were analyzed in accordance with the ORISE Laboratory Procedures Manual (ORISE 2007c). Soil samples were analyzed by gamma spectroscopy for thorium and uranium and results reported in units of picocuries per gram (pCi/g). Smears were analyzed for gross alpha and gross beta activity using a low background gas proportional counter. Smear data and direct measurements for total surface activity were converted to units of disintegrations per minute per 100 square centimeters $\left(\mathrm{dpm} / 100 \mathrm{~cm}^{2}\right)$. Additional information regarding survey and laboratory equipment and procedures is provided in Appendices A and B.

Site-specific DCGLs for building surfaces and soils have not been developed for the Scotia Depot. However, DCGL modeling was performed for two other DNSC Depots with identical usage scenarios; therefore, ORISE would expect that if site-specific DCGLs were required for the Scotia Depot, the results would be the same. Site-specific DCGL $\mathrm{DW}_{\mathbb{W}}$ for both Th-232 and U-238 on building surfaces and within soils were developed for the other two depots using the RESRAD (RESisual RADioactivity - a computer code developed at Argonne National Laboratory for the U.S. DOE) and RESRAD-BUILD computer codes and were approved by the NRC (ORISE 2006 and NRC 2007b). The $\mathrm{DCGL}_{\mathbb{W}} \mathrm{s}$ account for all decay products found in secular equilibrium, including, the slight natural contribution from U-235 and its decay products. The above background DCGL $\mathrm{S}$ for structural surfaces were $400 \mathrm{dpm} / 100 \mathrm{~cm}^{2}$ for Th-232 and its decay products and $800 \mathrm{dpm} / 100$ $\mathrm{cm}^{2}$ for U-238 and decay products. The above background DCGL $\mathrm{W}_{\mathbb{W}}$ for surface soils were determined to be $2.9 \mathrm{pCi} / \mathrm{g}$ for Th-232 and ranged from 2.2 to $2.5 \mathrm{pCi} / \mathrm{g}$ for U-238.

\section{FINDINGS AND RESULTS}

\section{Building Surface Scans}

Surface scan results for the scoping survey are discussed below under the respective survey classification sections. 


\section{Class 1 Buildings}

Gamma scans of Warehouses 505 and 506 were not particularly useful because of the generally elevated radiation levels due to ongoing tungsten storage. Two areas exhibiting slightly elevated gamma radiation levels were identified just outside of two doorways on each of the exterior docks of Warehouses 505 and 506. Additional investigation and direct measurement data attributed the elevated gamma readings to drums of tungsten stored just inside the warehouse. The gamma scans of the remaining Class 1 building areas did not identify gamma radiation discernable from background that was not otherwise associated with a construction material that exhibited slightly elevated gamma radiation levels.

Alpha-only, alpha plus beta and beta-only scans of the Class 1 building areas identified elevated radiation levels in a few localized locations in the repackaging area of Section 3 in WHSE 505. One location was noted on an upper ledge in Bay H21 and several floor and lower surface locations were noted on and surrounding a column located at the southwest corner of Bay H20. The remaining Class 1 building scans did not identify radiation levels distinguishable from background.

\section{Class 3 Buildings}

Gamma or alpha plus beta floor scans did not identify any elevated direct radiation levels associated with the Class 3 building areas. Similarly, alpha-only and beta-only scans did not identify any locations with elevated radiation levels distinguishable from background.

\section{Surface Activity Levels}

Total and removable surface activity levels are provided in Table 1. Total alpha and beta activities are summarized below for each building according to classification. All surface activity data presented represents net activity values above background. A cumulative distribution frequency was performed including every direct measurement taken onsite (Figure 13). The z-score of each measurement was calculated, which is the number of standard deviations above or below the mean of the data, and plotted against the surface activity level. A $z$-score of \pm 3 would require further investigation. Figure 13 clearly shows the two outliers. 


\section{Class 1 Buildings}

Total alpha and beta activity ranges are summarized in the table below. Individual measurement results are provided in Table 1.

\begin{tabular}{|c|c|c|c|}
\hline Buildings & $\begin{array}{c}\text { Total Alpha } \\
\text { Activity Range } \\
\left(\mathrm{dpm} / 100 \mathrm{~cm}^{2}\right) \\
\end{array}$ & $\begin{array}{c}\text { Total Beta } \\
\text { Activity Range } \\
\left(\mathrm{dpm} / 100 \mathrm{~cm}^{2}\right) \\
\end{array}$ & $\begin{array}{c}\text { Number of } \\
\text { Measurements } \\
>400 \mathrm{dpm} / 100 \mathrm{~cm}^{2} \\
\end{array}$ \\
\hline Warehouse 505 & -3 to 8 & -150 to 1,100 & 1 of 22 \\
\hline Warehouse 506 & -3 to 8 & -180 to 130 & 0 of 26 \\
\hline Building 12 (Garage) & -4 to 0 & -85 to 110 & 0 of 10 \\
\hline Building 14 & -2 to 8 & -100 to 130 & 0 of 13 \\
\hline
\end{tabular}

The results shown above and detailed in Table 1 indicate only one location in WHSE 505 with beta activity above background. The measurement was taken on an upper ledge in Bay H21 and was verified to be a small localized location of low-level contamination. The elevated readings on and surrounding the column located at the southwest corner of Bay H20 in WHSE 505 were attributed to elevated radiation levels measured from the drums of tungsten stored nearby. Removable activities ranged from 0 to $3 \mathrm{dpm} / 100 \mathrm{~cm}^{2}$ for gross alpha and from -5 to $5 \mathrm{dpm} / 100 \mathrm{~cm}^{2}$ for gross beta.

\section{Class 3 Buildings}

Total alpha and beta activity ranges for Class 3 building ranges are summarized in the table below. Individual measurement location results are provided in Table 1.

\begin{tabular}{|c|c|c|c|}
\hline Buildings & $\begin{array}{c}\text { Total Alpha } \\
\text { Activity Range } \\
\left(\mathrm{dpm} / 100 \mathrm{~cm}^{2}\right) \\
\end{array}$ & $\begin{array}{c}\text { Total Beta } \\
\text { Activity Range } \\
\left(\mathrm{dpm} / 100 \mathrm{~cm}^{2}\right) \\
\end{array}$ & $\begin{array}{c}\text { Number of } \\
\text { Measurements } \\
>400 \mathrm{dpm} / 100 \mathrm{~cm}^{2} \\
\end{array}$ \\
\hline Building 22 & -3 to 2 & -200 to 28 & 0 of 7 \\
\hline Building 23 & -4 to 1 & -52 to 450 & 1 of 12 \\
\hline
\end{tabular}


The results shown above and detailed in Table 1 indicate one location in Building 23 with beta activity potentially above background. The location could be the result of a higher construction material background or statistical anomaly. Further investigation would be required to either substantiate the area as contaminated or eliminate the location as suspect contamination. Removable activity for the Class 3 buildings ranged from 0 to $3 \mathrm{dpm} / 100 \mathrm{~cm}^{2}$ and -5 to $4 \mathrm{dpm} / 100$ $\mathrm{cm}^{2}$ for gross alpha and gross beta, respectively.

\section{Exterior Surface Scans}

Surface scan results for exterior land areas are described below under the respective survey classification sections.

\section{Class 1 Land Areas}

There were no Class 1 land areas identified during the HSA.

\section{Class 2 Land Areas}

Gamma scans of the land areas that were designated as Class 2 identified numerous locations with slightly elevated gamma radiation (nearly twice typical background). The radiation levels were the highest around the perimeter of the two warehouses (Figure 11). Five locations were flagged for sampling.

\section{Class 3 Land Areas}

Surface scans of the Class 3 land areas also identified locations of slightly elevated direct gamma radiation (Figure 11). The highest density for the Class 3 area was the northwest corner of the site. Two locations were flagged for sampling due to the slightly elevated radiation levels and a third location was selected (S004) to be used as a background reference sample.

\section{Radionuclide Concentrations in Soil Samples}

The concentrations of Th-232 and U-238 for individual soil samples are provided in Table 2 . The table on page 14 provides a summary of the range of activities. All radionuclide concentration data 
presented are gross data that have not been corrected for background contributions. Sample S004 was selected as a preliminary background reference sample and was collected from a picnic area in between Buildings 12 and 14. This area appears to be one of the few if not the only non-impacted grassy area of the site.

\begin{tabular}{|c|c|c|c|}
\hline \multirow{2}{*}{ Area } & \multicolumn{3}{|c|}{$\begin{array}{l}\text { Radionuclide Concentration } \\
\qquad(\mathrm{pCi} / \mathrm{g})\end{array}$} \\
\hline & $\begin{array}{l}\text { Number of } \\
\text { Samples }\end{array}$ & Th-232 & $\mathrm{U}-238$ \\
\hline Class 2 Samples & 5 & 0.57 to 0.75 & 0.53 to 0.95 \\
\hline Class 3 Samples & 2 & 0.72 to 0.76 & 0.66 \\
\hline Sample 004 & 1 & 0.44 & 0.58 \\
\hline
\end{tabular}

The analytical results did not identify Th-232 or U-238 concentrations in soil samples above levels consistent with natural background concentrations.

\section{DISCUSSION OF RESULTS}

The contaminant of concern for the Scotia Depot is primarily thorium with the potential for lesser quantities of uranium. The results of the scoping survey identified one definitive location of low-level contamination on an upper ledge of the repackaging area of WHSE 505. The activity of the localized location was 1,100 beta $\mathrm{dpm} / 100 \mathrm{~cm}^{2}$. The highest activity measured in a Class 3 structure was limited to one location in Building 23 measuring 450 beta dpm/100 $\mathrm{cm}^{2}$. Surveys did not identify any indications of residual activity within any of the remaining buildings.

Surface scans of the land areas identified locations of slightly elevated direct gamma radiation. Generally the readings were the highest around the perimeter of the two warehouses and in the northwest corner of the site. The analytical results did not identify residual contamination present in the soil samples. 


\section{SUMMARY AND RECOMMENDATIONS}

At the request of the Defense Logistics Agency, the Oak Ridge Institute for Science and Education conducted radiological scoping surveys of the Scotia Depot during the period of September 24 through 27, 2007. The scoping survey included visual inspections and limited radiological surveys performed in accordance with area classification that included surface scans, total and removable activity measurements, and soil sampling.

The overall results of the scoping survey validated the initial findings for building classifications provided in the Historical Site Assessment. One localized area of contamination was confirmed in WHSE 505. Of the remaining buildings that were surveyed, only one additional measurement in Building 23 is suspect. Land area surveys identified numerous locations with slightly elevated direct gamma radiation levels. None of the soil samples contained Th-232 or U-238 concentrations above expected background concentrations which typically range from 0.5 to $1.5 \mathrm{pCi} / \mathrm{g}$. These values were verified by performing a search of background soil samples that have been collected in New York and archived by the Environmental Measurements Laboratory in an online soil database (EML).

Recommendations for future building characterizations include expanded surveys in Warehouses 505 and 506. Removal of the tungsten materials currently stored within the Warehouses is strongly recommended to reduce the ambient gamma background and eliminate the interference that was experienced when performing scans and direct measurements. Removal of the materials will also allow unlimited access to the warehouse's interior surfaces. Now that contamination has been confirmed in Warehouse 505, a more extensive survey effort should be considered. As for the remaining Class 1 and 3 buildings, surface scans of the upper surfaces (above 2 meters) should be performed. The one suspect location in Building 23 would require investigation to determine whether it is the result of low-level contamination, a higher construction material background or a statistical anomaly. If contamination is confirmed in Building 23, the building should be reclassified and surveys expanded. For the remaining buildings, additional survey data could be collected at any time to fulfill the requirements for final status survey data (quantity and quality considered) and the data could be evaluated further once a site-specific DCGL is approved. Additional soil sampling may be necessary in the development of site specific DCGLs. Otherwise, final status survey soil sampling could be planned and performed once a site-specific DCGL is approved. 


\section{FIGURES}




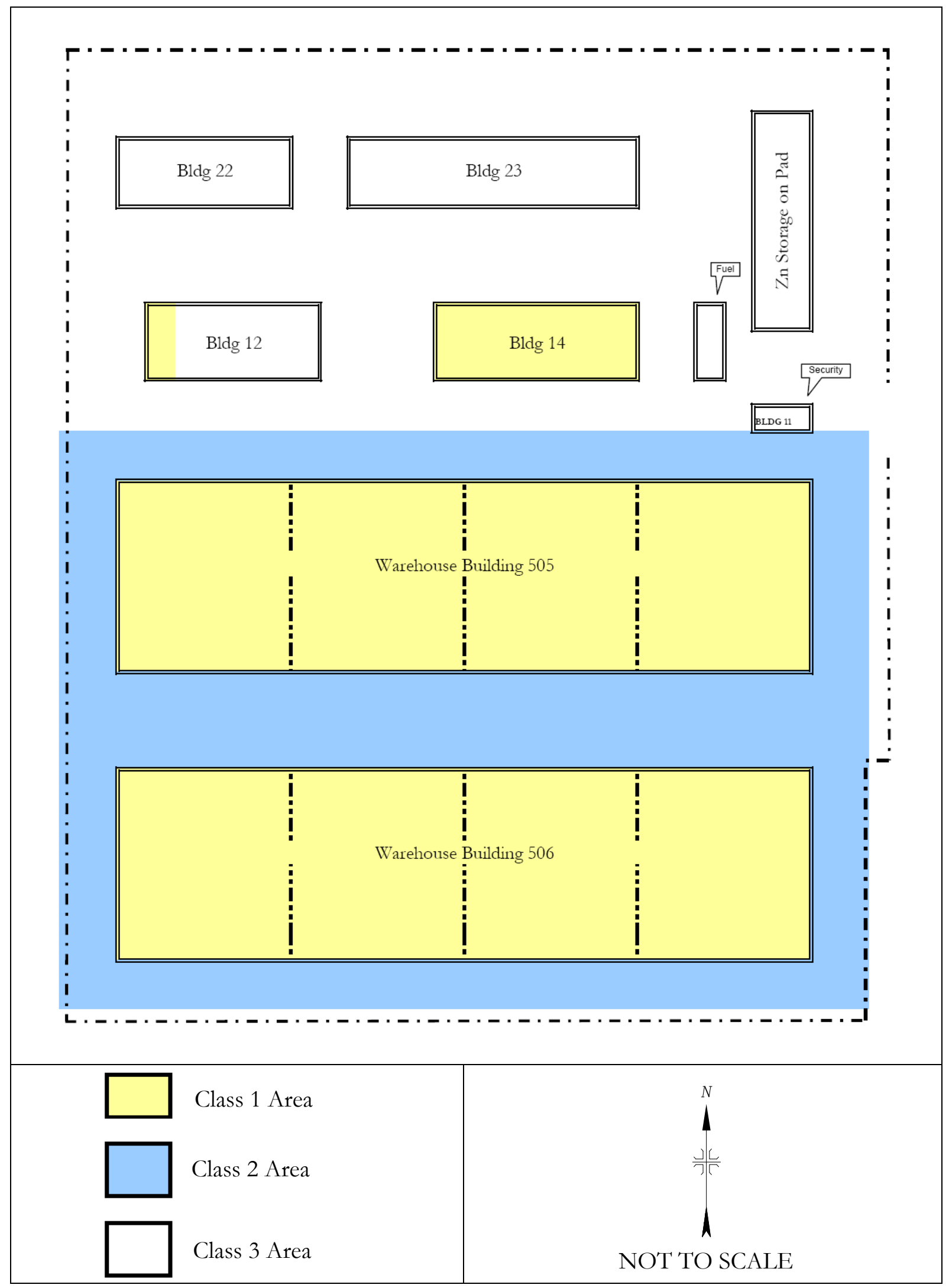

Figure 1: Conceptual Site Model 


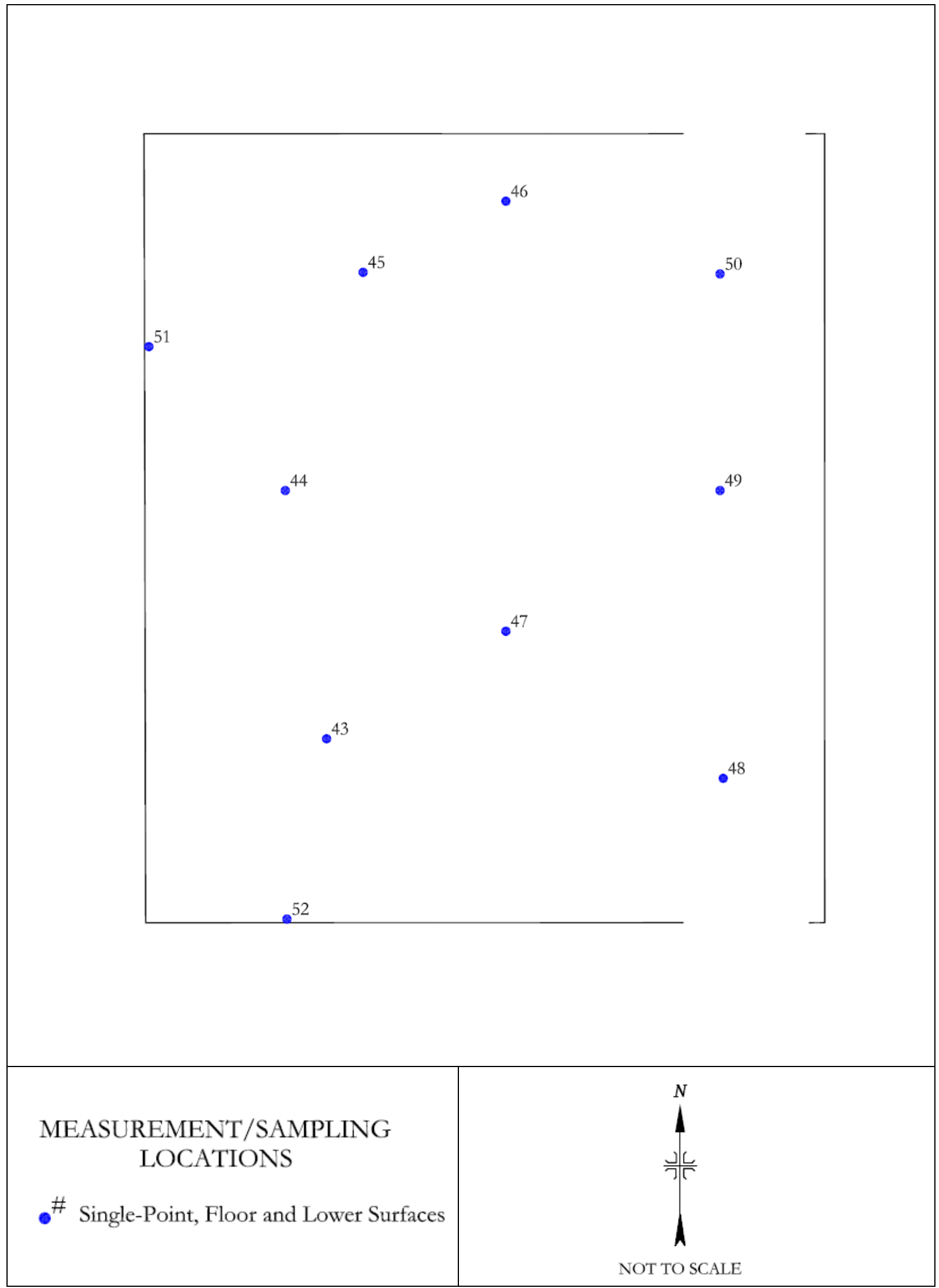

Figure 2: Building 12, Garage - Direct Measurement and Sample Locations 


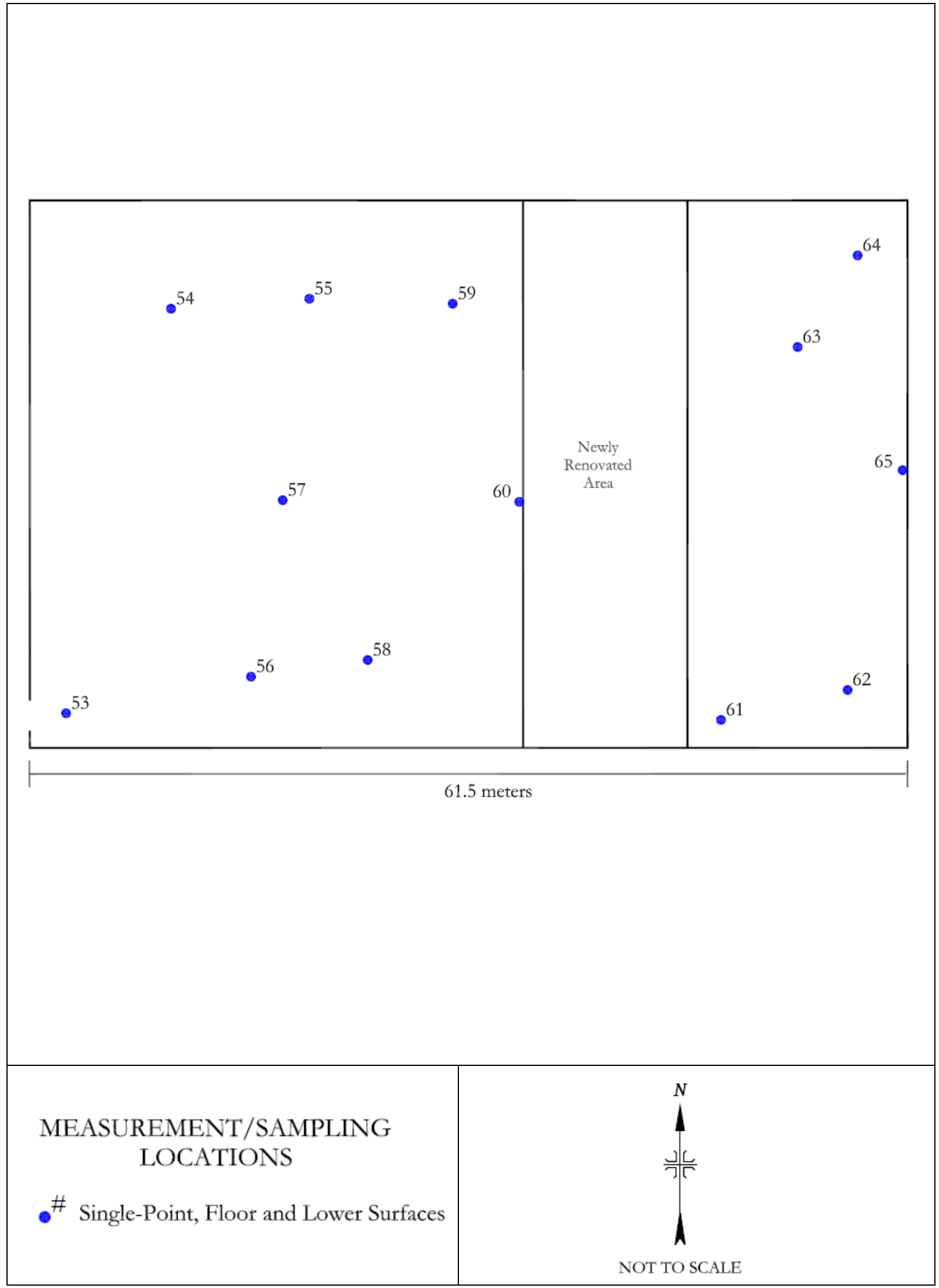

Figure 3: Building 14 - Direct Measurement and Sample Locations 


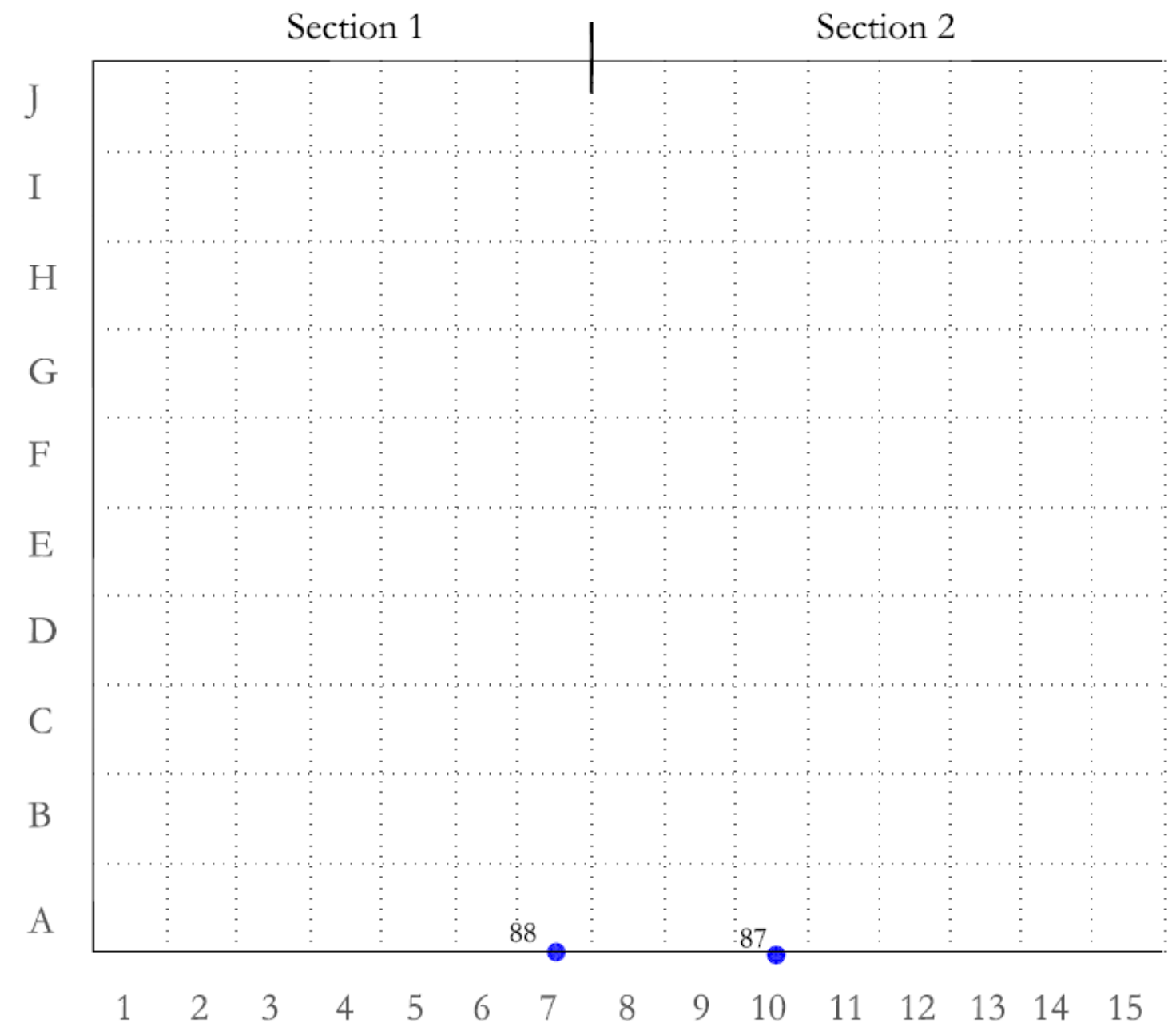

MEASUREMENT/SAMPLING LOCATIONS

\# Single-Point, Floor and Lower Surfaces

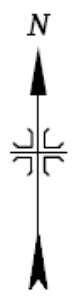

NOT TO SCALE

Figure 4: Building 505, Sections 1 \& 2 - Direct Measurement and Sample Locations 


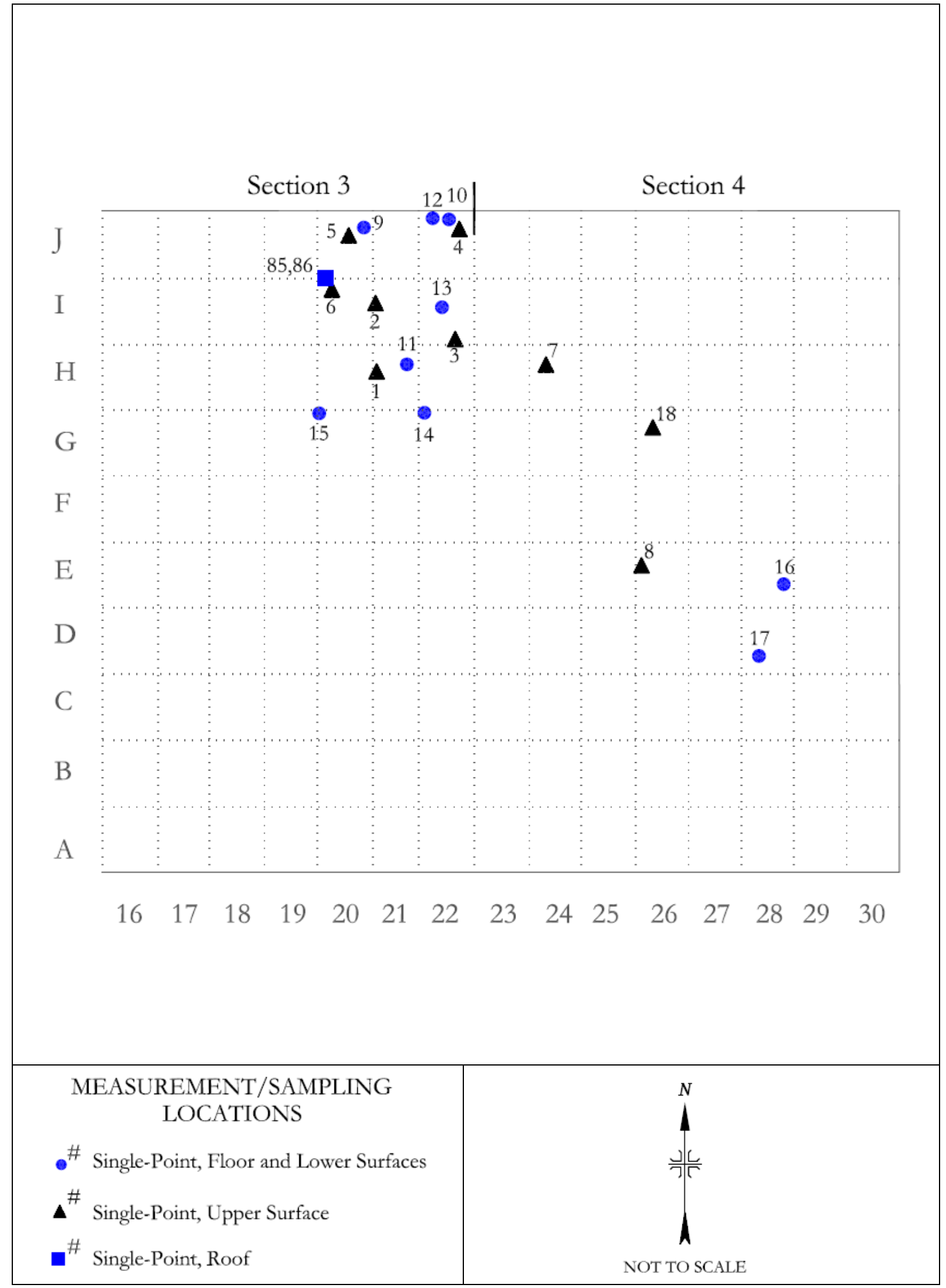

Figure 5: Building 505, Sections 3 \& 4 - Direct Measurement and Sample Locations 


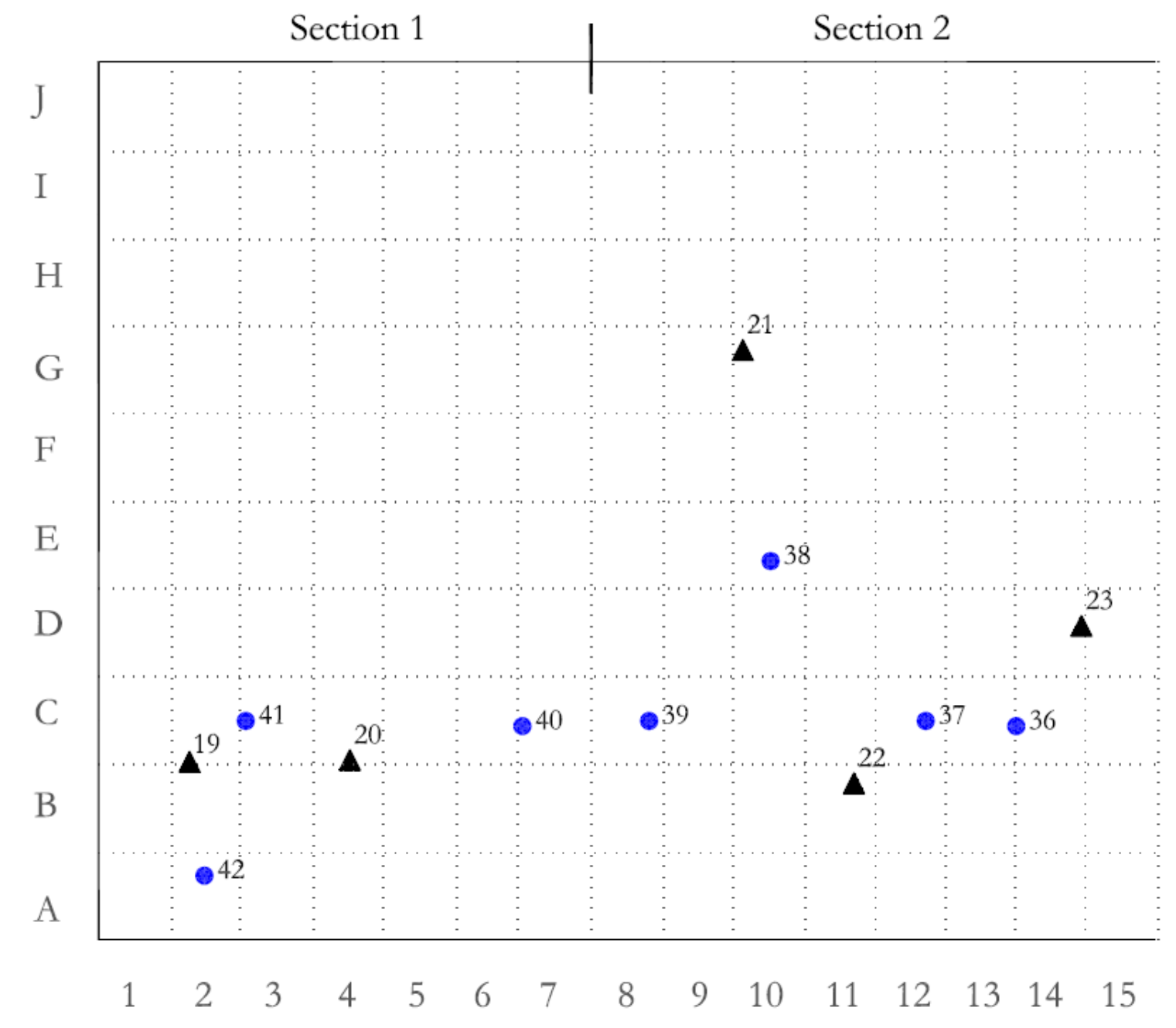

\section{MEASUREMENT/SAMPLING LOCATIONS}

- Single-Point, Floor and Lower Surfaces

$\Delta^{\#}$ Single-Point, Upper Surface

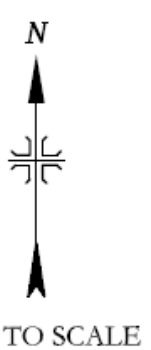

Figure 6: Building 506, Sections 1 \& 2-Direct Measurement and Sample Locations 


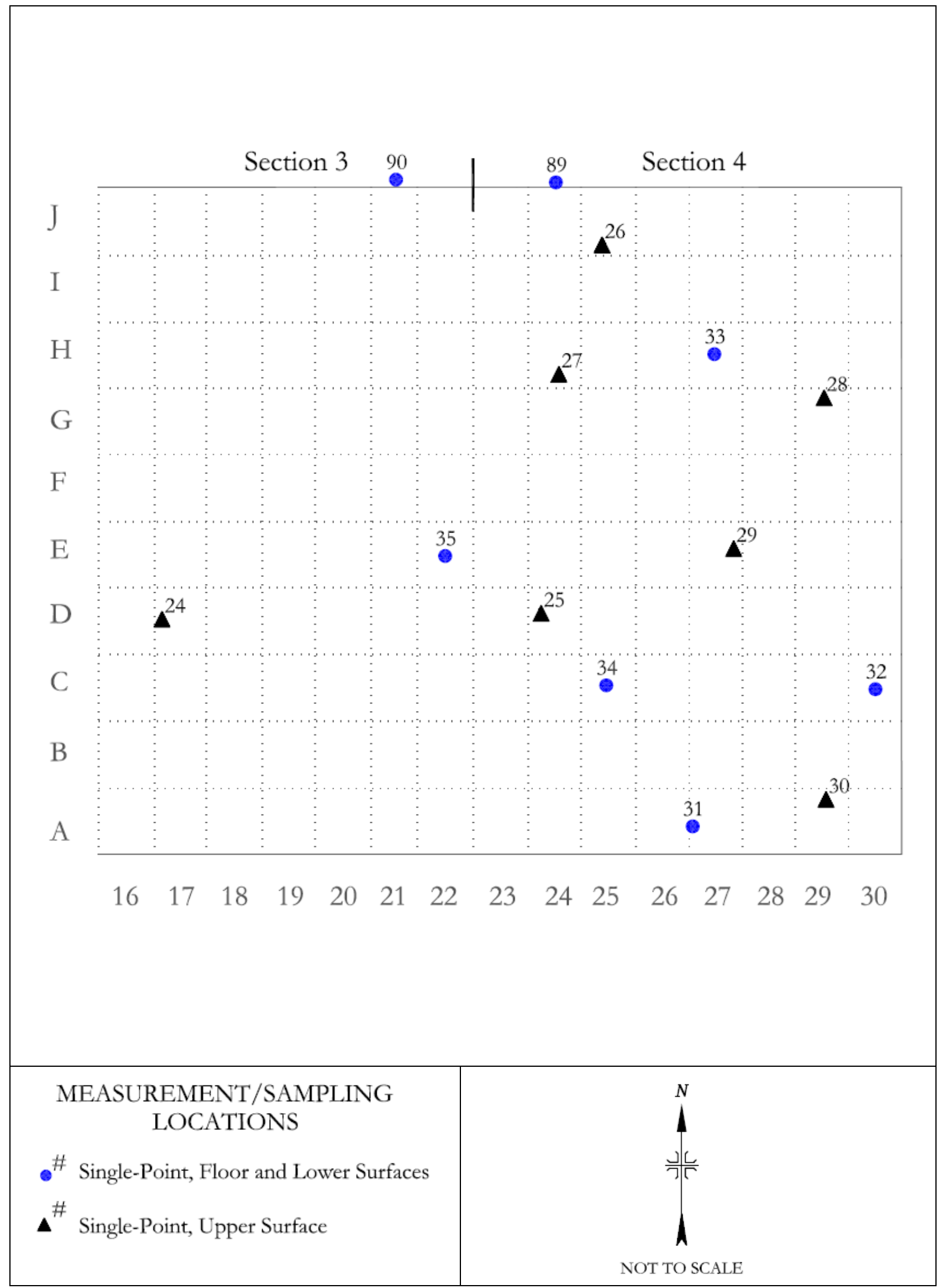

Figure 7: Building 506, Sections 3 \& 4 - Direct Measurement and Sample Locations 


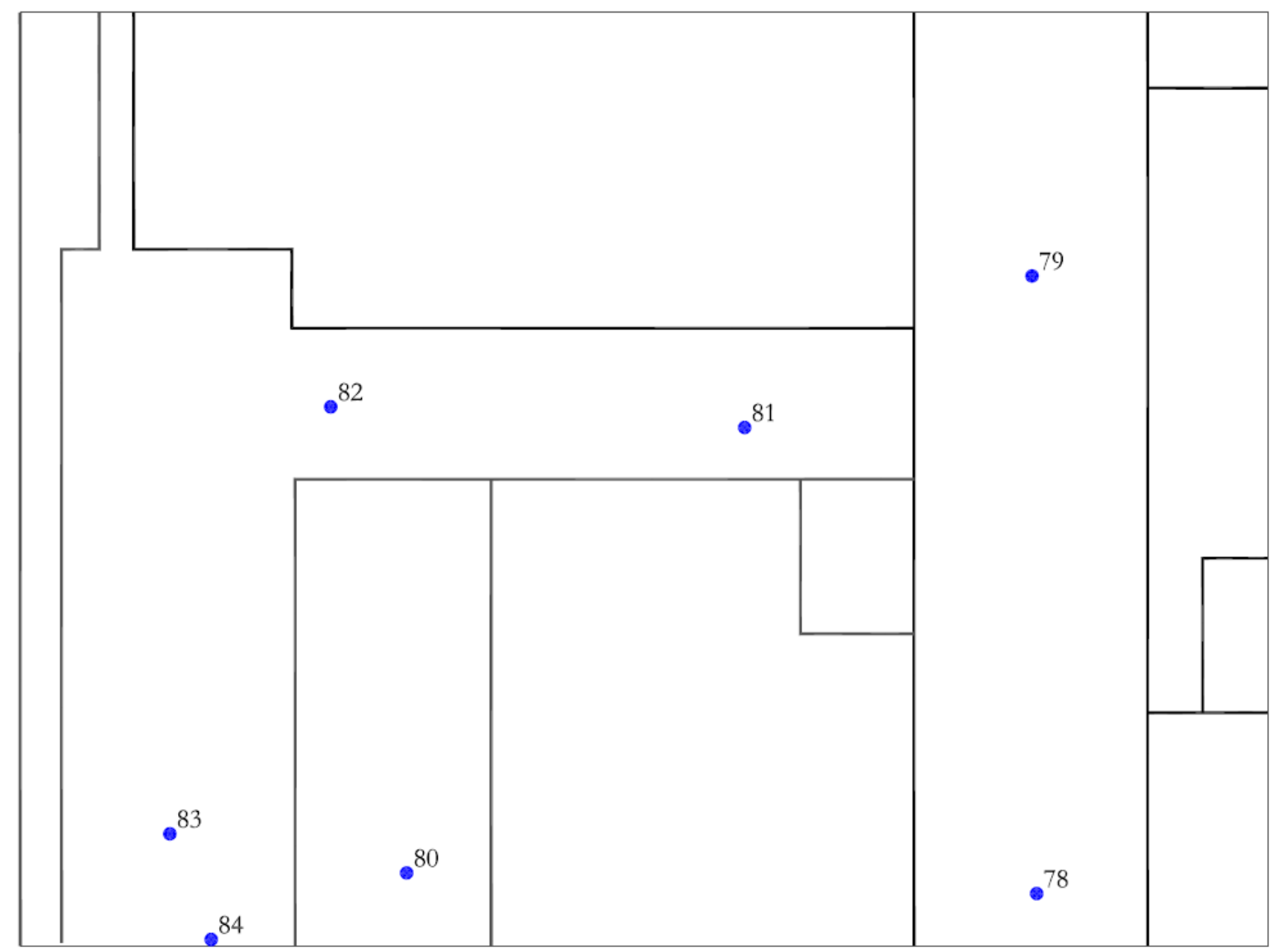

MEASUREMENT/SAMPLING LOCATIONS

- Single-Point, Floor and Lower Surfaces

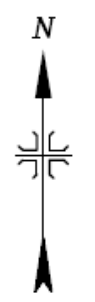

NOT TO SCALE

Figure 8: Building 22 - Direct Measurement and Sample Locations 


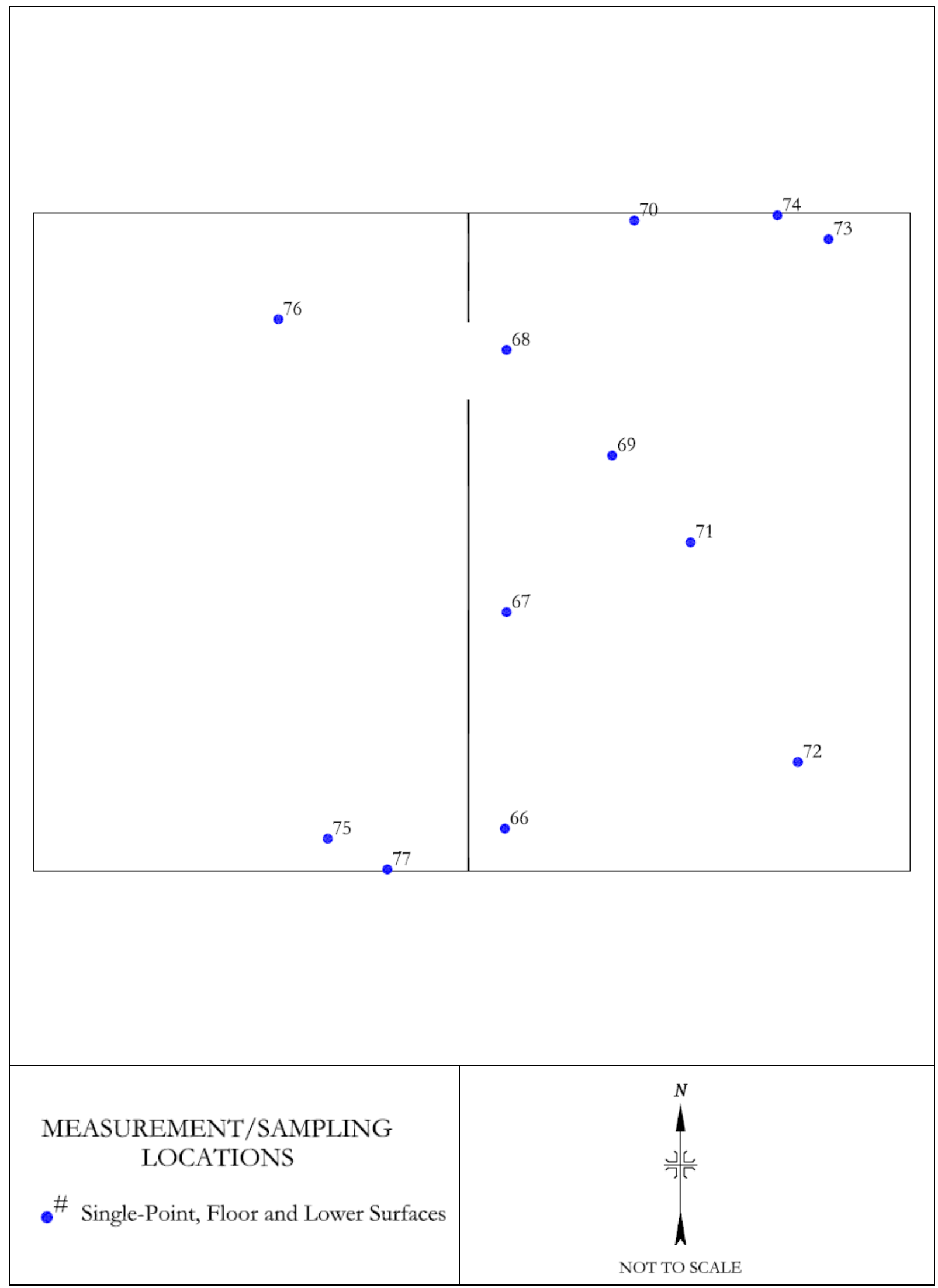

Figure 9: Building 23 - Direct Measurement and Sample Locations 


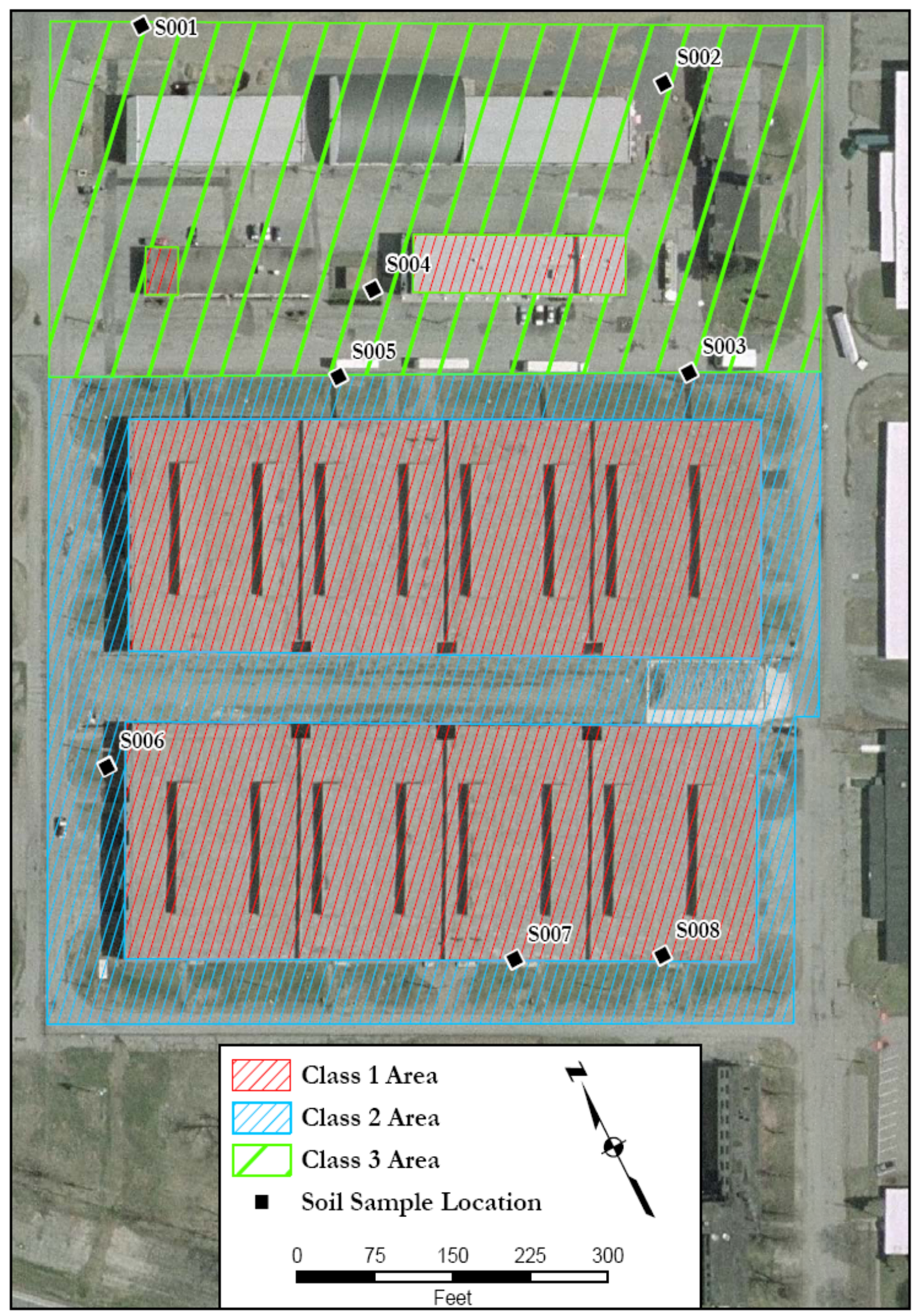

Figure 10: Site Plot Plan with Area Classifications 


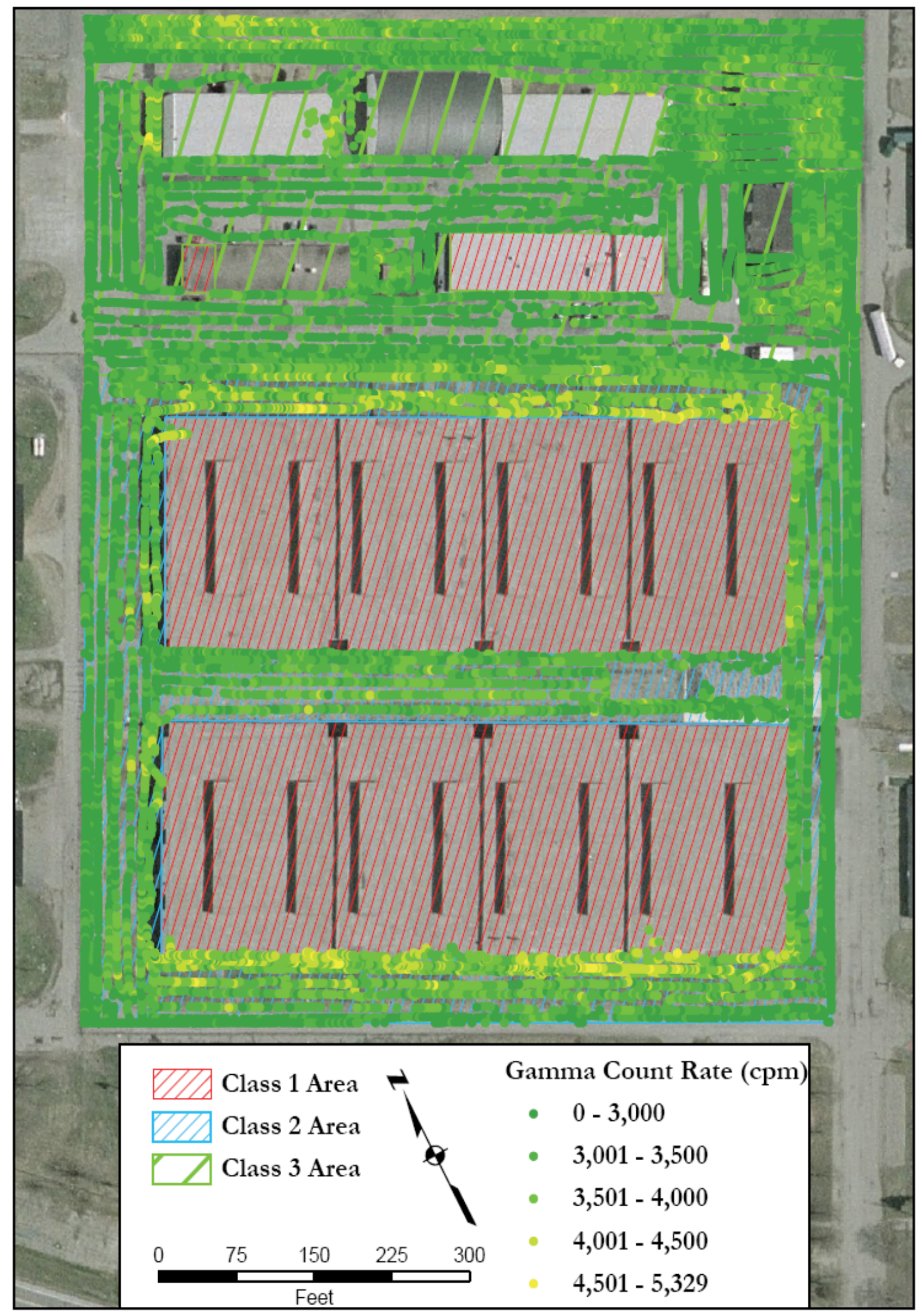

Figure 11: Gamma Scan Results 


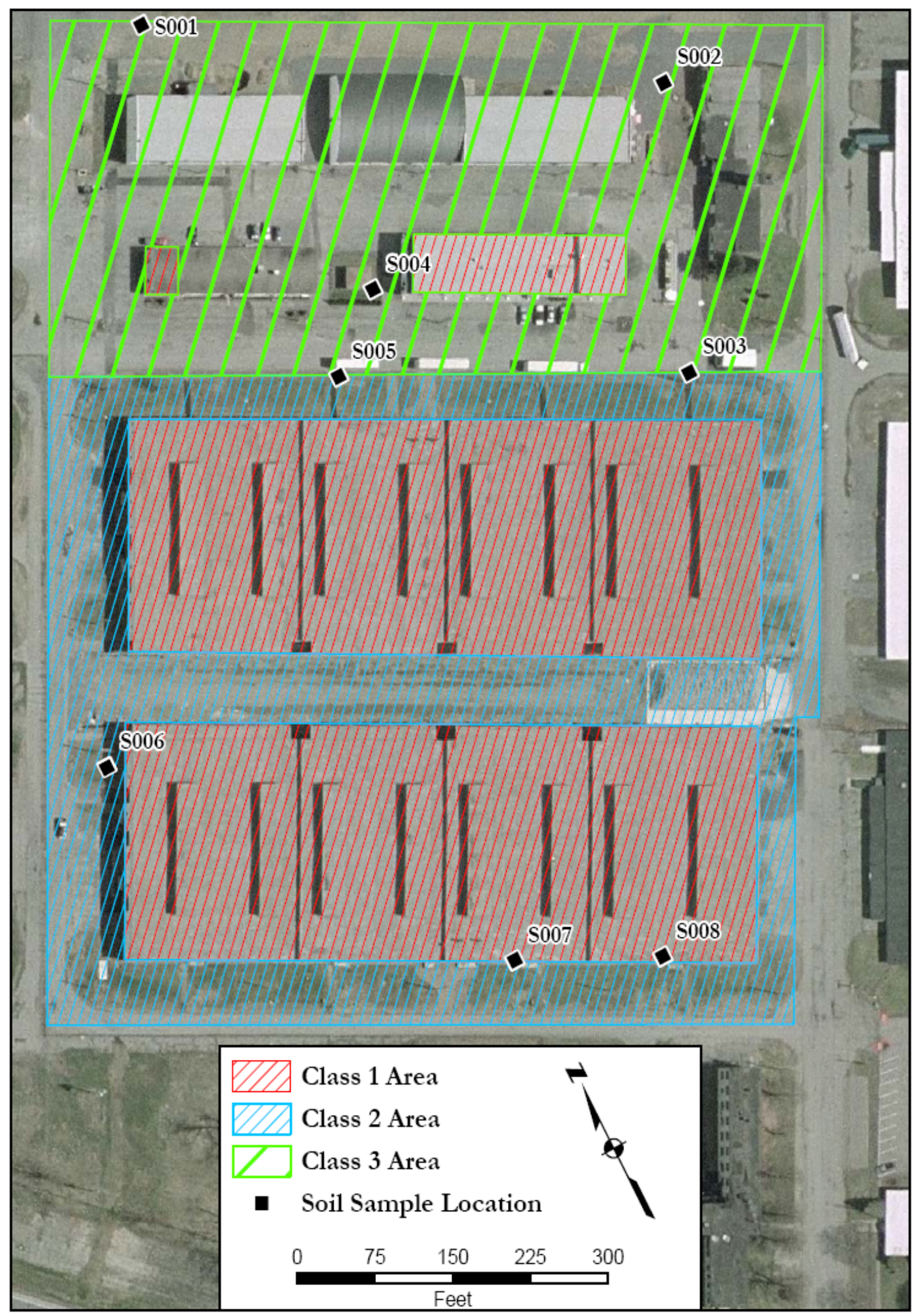

Figure 12: Soil Sample Locations 


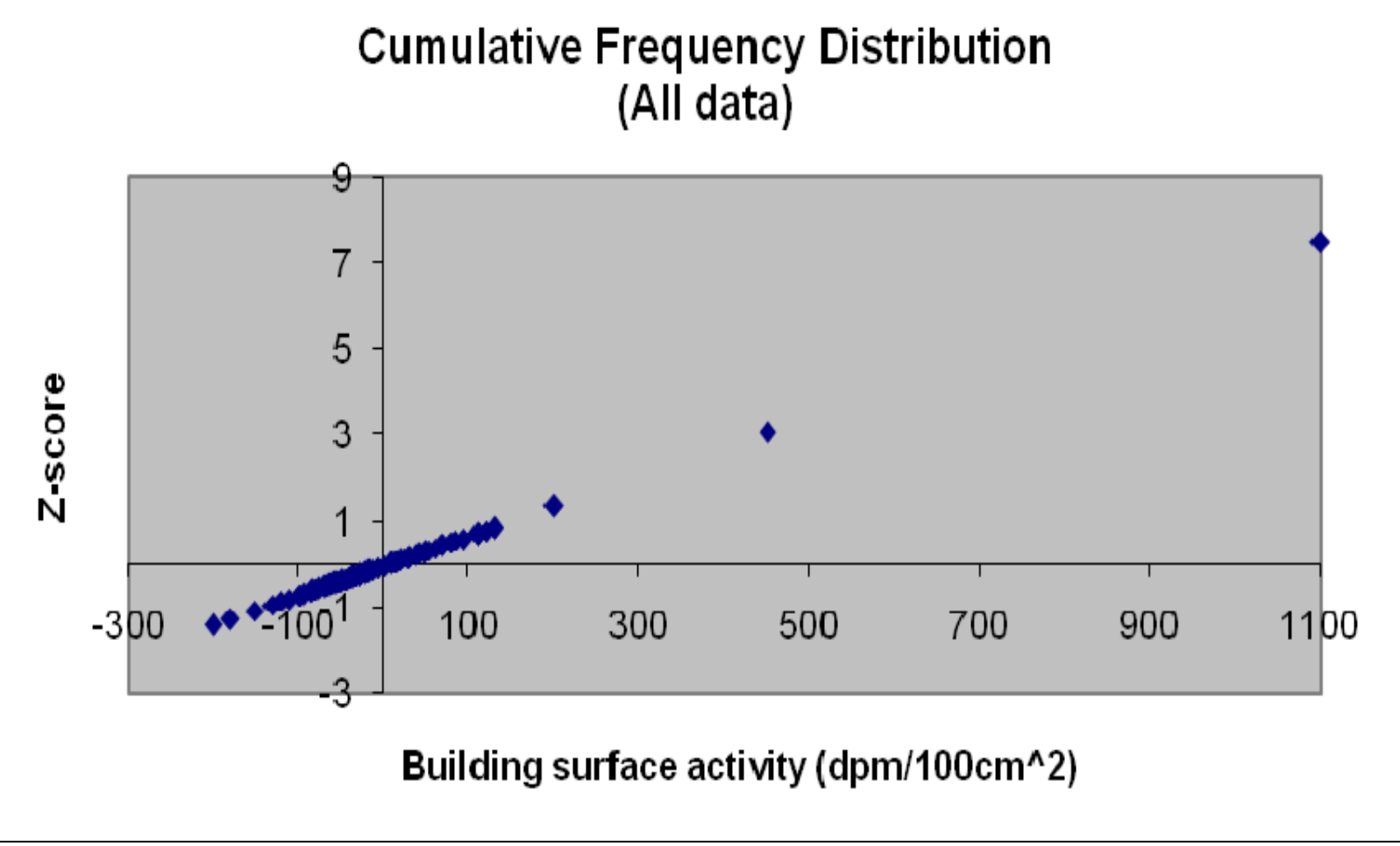

Figure 13: Cumulative Frequency Distribution 


\section{TABLES}


TABLE 1

\section{SURFACE ACTIVITY LEVELS SCOTIA DEPOT SCOTIA, NEW YORK}

\begin{tabular}{|c|c|c|c|c|c|}
\hline \multirow{2}{*}{$\begin{array}{c}\text { Building (Class) } \\
\text { Measurement } \\
\text { Location }^{\mathrm{a}}\end{array}$} & \multirow[t]{2}{*}{ Surface $^{b}$} & \multicolumn{2}{|c|}{$\begin{array}{l}\text { Total Activity } \\
\left(\mathrm{dpm} / 100 \mathrm{~cm}^{2}\right)\end{array}$} & \multicolumn{2}{|c|}{$\begin{array}{c}\text { Removable Activity } \\
\left(\mathrm{dpm} / 100 \mathrm{~cm}^{2}\right)\end{array}$} \\
\hline & & Alpha & Beta & Alpha & Beta \\
\hline \multicolumn{6}{|l|}{ Warehouse 505 (1) } \\
\hline 1 & US & 2 & $1,100^{\mathrm{d}}$ & 0 & 2 \\
\hline 2 & US & 8 & 200 & 0 & 1 \\
\hline 3 & US & 5 & -35 & 0 & 4 \\
\hline 4 & US & 2 & -150 & 1 & -2 \\
\hline 5 & US & 0 & 22 & 1 & -1 \\
\hline 6 & US & -1 & -6 & 0 & -1 \\
\hline 7 & US & -3 & 17 & 0 & 1 \\
\hline 8 & US & 3 & -28 & 0 & -4 \\
\hline 9 & $\mathrm{~F}$ & 2 & -39 & 0 & 5 \\
\hline 10 & $\mathrm{~F}$ & 1 & -44 & 0 & 3 \\
\hline 11 & $\mathrm{~F}$ & 2 & 48 & 0 & 4 \\
\hline 12 & LS & -3 & -22 & 0 & 1 \\
\hline 13 & $\mathrm{~F}$ & -2 & 61 & 1 & -5 \\
\hline 14 & LS & 2 & -76 & 0 & -2 \\
\hline 15 & LS & 0 & 9 & 0 & -2 \\
\hline 16 & $\mathrm{~F}$ & 2 & -120 & 0 & -1 \\
\hline 17 & $\mathrm{~F}$ & 5 & -63 & 0 & -1 \\
\hline 18 & US & 3 & 39 & 1 & -2 \\
\hline 85 & Roof & 0 & 20 & 0 & 5 \\
\hline 86 & Roof & -2 & -130 & 0 & 2 \\
\hline 87 & Dock & 0 & 70 & 1 & 3 \\
\hline 88 & Dock & 2 & 120 & 0 & 2 \\
\hline \multicolumn{6}{|l|}{ Warehouse 506 (1) } \\
\hline 19 & US & 4 & -46 & 0 & -1 \\
\hline 20 & US & 2 & -57 & 1 & -4 \\
\hline 21 & US & -2 & -83 & 0 & -2 \\
\hline 22 & US & 1 & 130 & 1 & -2 \\
\hline 23 & US & 5 & 50 & 1 & -3 \\
\hline 24 & US & 8 & 15 & 1 & -2 \\
\hline 25 & US & 4 & -59 & 3 & 1 \\
\hline 26 & US & 5 & -55 & 1 & 1 \\
\hline 27 & US & 8 & -61 & 3 & -1 \\
\hline 28 & US & 4 & $\begin{array}{l}-79 \\
\end{array}$ & 0 & -1 \\
\hline 29 & US & 1 & 20 & 0 & 5 \\
\hline 30 & US & 4 & -79 & 0 & 3 \\
\hline 31 & $\mathrm{~F}$ & -1 & -28 & 0 & -1 \\
\hline
\end{tabular}


TABLE 1 (Continued)

\section{SURFACE ACTIVITY LEVELS \\ SCOTIA DEPOT \\ SCOTIA, NEW YORK}

\begin{tabular}{|c|c|c|c|c|c|}
\hline \multirow{2}{*}{$\begin{array}{c}\text { Building (Class) } \\
\text { Measurement } \\
\text { Location }^{\mathrm{a}}\end{array}$} & \multirow[t]{2}{*}{ Surface $^{\mathrm{b}}$} & \multicolumn{2}{|c|}{$\begin{array}{l}\text { Total Activity } \\
\left(\mathrm{dpm} / 100 \mathrm{~cm}^{2}\right)\end{array}$} & \multicolumn{2}{|c|}{$\begin{array}{l}\text { Removable Activity } \\
\left(\mathrm{dpm} / 100 \mathrm{~cm}^{2}\right)\end{array}$} \\
\hline & & Alpha & Beta & Alpha & Beta \\
\hline \multicolumn{6}{|c|}{ Warehouse 506 (1) (Continued) } \\
\hline 32 & $\mathrm{~F}$ & -2 & 120 & 0 & -5 \\
\hline 33 & $\mathrm{~F}$ & 2 & -15 & 1 & -3 \\
\hline 34 & $\mathrm{~F}$ & 0 & -44 & 1 & -3 \\
\hline 35 & $\mathrm{~F}$ & 5 & 30 & 0 & -1 \\
\hline 36 & $\mathrm{~F}$ & 4 & 94 & 0 & -1 \\
\hline 37 & $\mathrm{~F}$ & -3 & 30 & 1 & -3 \\
\hline 38 & $\mathrm{~F}$ & 5 & -54 & 1 & 2 \\
\hline 39 & $\mathrm{~F}$ & 0 & -98 & 1 & -1 \\
\hline 40 & $\mathrm{~F}$ & -1 & -94 & 1 & 3 \\
\hline 41 & $\mathrm{~F}$ & -1 & 54 & 1 & 1 \\
\hline 42 & $\mathrm{~F}$ & -1 & -110 & 0 & -2 \\
\hline 89 & Dock & -2 & -180 & 0 & -4 \\
\hline 90 & Dock & -1 & 110 & 1 & -3 \\
\hline \multicolumn{6}{|c|}{ Building 12 - Garage (1) } \\
\hline 43 & $\mathrm{~F}$ & 0 & 81 & 0 & -1 \\
\hline 44 & $\mathrm{~F}$ & -1 & -70 & 0 & 1 \\
\hline 45 & $\mathrm{~F}$ & -2 & -31 & 0 & -2 \\
\hline 46 & $\mathrm{~F}$ & -4 & -39 & 0 & 3 \\
\hline 47 & $\mathrm{~F}$ & -2 & 110 & 0 & -1 \\
\hline 48 & $\mathrm{~F}$ & -2 & -35 & 0 & -5 \\
\hline 49 & $\mathrm{~F}$ & -2 & -68 & 0 & 4 \\
\hline 50 & $\mathrm{~F}$ & -2 & -85 & 0 & -3 \\
\hline 51 & LS & -2 & 13 & 0 & -2 \\
\hline 52 & LS & -1 & 70 & 1 & 2 \\
\hline \multicolumn{6}{|l|}{\begin{tabular}{|l|} 
Building 14 (1) \\
\end{tabular}} \\
\hline 53 & $\mathrm{~F}$ & -2 & 79 & 1 & 1 \\
\hline 54 & $\mathrm{~F}$ & -2 & 130 & 0 & -3 \\
\hline 55 & $\mathrm{~F}$ & 0 & 2 & 1 & -1 \\
\hline 56 & $\mathrm{~F}$ & -1 & 15 & 1 & 3 \\
\hline 57 & $\mathrm{~F}$ & 2 & -100 & 0 & -3 \\
\hline 58 & $\mathrm{~F}$ & -2 & 9 & 0 & 3 \\
\hline 59 & $\mathrm{~F}$ & 0 & -50 & 0 & -1 \\
\hline 60 & LS & 0 & -18 & 0 & -2 \\
\hline 61 & $\mathrm{~F}$ & -2 & -100 & 0 & 2 \\
\hline 62 & $\mathrm{~F}$ & 1 & -28 & 1 & -2 \\
\hline 63 & $\mathrm{~F}$ & 8 & 20 & 1 & -2 \\
\hline
\end{tabular}


TABLE 1 (Continued)

\section{SURFACE ACTIVITY LEVELS \\ SCOTIA DEPOT \\ SCOTIA, NEW YORK}

\begin{tabular}{|c|c|c|c|c|c|}
\hline \multirow{2}{*}{$\begin{array}{c}\text { Building (Class) } \\
\text { Measurement } \\
\text { Location }^{\mathrm{a}} \\
\end{array}$} & \multirow[t]{2}{*}{ Surface $^{b}$} & \multicolumn{2}{|c|}{$\begin{array}{l}\text { Total Activity } \\
\left(\mathrm{dpm} / 100 \mathrm{~cm}^{2}\right)\end{array}$} & \multicolumn{2}{|c|}{$\begin{array}{c}\text { Removable Activity } \\
\left(\mathrm{dpm} / 100 \mathrm{~cm}^{2}\right)\end{array}$} \\
\hline & & Alpha & Beta & Alpha & Beta \\
\hline \multicolumn{6}{|c|}{ Building 14 (1) (Continued) } \\
\hline 64 & $\mathrm{~F}$ & 2 & -41 & 0 & -3 \\
\hline 65 & LS & 7 & -13 & 0 & -1 \\
\hline \multicolumn{6}{|l|}{ Building 23 (3) } \\
\hline 66 & $\mathrm{~F}$ & -3 & -50 & 0 & -2 \\
\hline 67 & $\mathrm{~F}$ & -2 & -22 & 0 & -1 \\
\hline 68 & $\mathrm{~F}$ & -1 & 110 & 1 & -2 \\
\hline 69 & $\mathrm{~F}$ & -1 & 42 & 0 & -2 \\
\hline 70 & LS & -1 & -52 & 0 & 1 \\
\hline 71 & $\mathrm{~F}$ & -1 & -37 & 0 & -4 \\
\hline 72 & $\mathrm{~F}$ & 1 & 30 & 0 & 3 \\
\hline 73 & $\mathrm{~F}$ & -1 & 48 & 0 & 4 \\
\hline 74 & LS & 1 & -33 & 0 & -1 \\
\hline 75 & $\mathrm{~F}$ & -2 & 37 & 0 & -2 \\
\hline 76 & $\mathrm{~F}$ & -4 & 85 & 3 & 2 \\
\hline 77 & LS & 1 & 450 & 0 & 3 \\
\hline \multicolumn{6}{|l|}{ Building 22 (3) } \\
\hline 78 & $\mathrm{~F}$ & -1 & 28 & 0 & -2 \\
\hline 79 & $\mathrm{~F}$ & -1 & -66 & 1 & -1 \\
\hline 80 & $\mathrm{~F}$ & -1 & -17 & 0 & 2 \\
\hline 81 & $\mathrm{~F}$ & -3 & -200 & 0 & -1 \\
\hline 82 & $\mathrm{~F}$ & -3 & -7 & 0 & -5 \\
\hline 83 & $\mathrm{~F}$ & 2 & -28 & 1 & 2 \\
\hline 84 & LS & 2 & -83 & 1 & -3 \\
\hline
\end{tabular}

aRefer to Figures 2 through 9.

$\mathrm{bF}=$ floor, $\mathrm{LS}=$ lower surface, US=upper surface.

cData represent net surface activity levels that have been corrected for background contributions.

$\mathrm{d}$ Measurement performed using a smaller G-M probe. 
TABLE 2

RADIONUCLIDE CONCENTRATIONS IN SOIL SAMPLES

SCOTIA DEPOT

SCOTIA, NEW YORK

\begin{tabular}{|c|c|c|c|c|c|}
\hline \multirow{2}{*}{ Sample ID/Class ${ }^{\mathrm{a}, \mathrm{b}}$} & \multirow{2}{*}{ GPS Coordinate ${ }^{c}$} & \multicolumn{4}{|c|}{ Radionuclide Concentration (pCi/g) } \\
\hline & & Th-232 & Total Thorium & $\mathrm{U}-238$ & Total Uranium \\
\hline S001 / 3 & $1460035 \mathrm{~N}, 629791 \mathrm{E}$ & $0.76 \pm 0.13^{\mathrm{e}}$ & $1.46 \pm 0.14$ & $0.66 \pm 0.44$ & $1.32 \pm 0.88$ \\
\hline S002 / 3 & $1459755 \mathrm{~N}, 630214 \mathrm{~W}$ & $0.72 \pm 0.14$ & $1.42 \pm 0.15$ & $0.66 \pm 0.56$ & $1.3 \pm 1.1$ \\
\hline S003 / 2 & $1459518 \mathrm{~N}, 630119 \mathrm{E}$ & $0.75 \pm 0.13$ & $1.50 \pm 0.14$ & $0.95 \pm 0.46$ & $1.90 \pm 0.92$ \\
\hline $\mathrm{S} 004^{\mathrm{f}} / 3$ & $1459715 \mathrm{~N}, 629877 \mathrm{E}$ & $0.44 \pm 0.14$ & $0.90 \pm 0.15$ & $0.58 \pm 0.40$ & $1.14 \pm 0.80$ \\
\hline S005 / 2 & $1459659 \mathrm{~N}, 629810 \mathrm{E}$ & $0.67 \pm 0.15$ & $1.28 \pm 0.16$ & $0.64 \pm 0.53$ & $1.3 \pm 1.1$ \\
\hline S006 / 2 & $1459433 \mathrm{~N}, 629446 \mathrm{E}$ & $0.57 \pm 0.11$ & $1.13 \pm 0.12$ & $0.73 \pm 0.41$ & $1.49 \pm 0.82$ \\
\hline S007 / 2 & $1459103 \mathrm{~N}, 629712 \mathrm{E}$ & $0.75 \pm 0.15$ & $1.45 \pm 0.16$ & $0.80 \pm 0.45$ & $1.61 \pm 0.90$ \\
\hline S008 / 2 & $1459040 \mathrm{~N}, 629841 \mathrm{E}$ & $0.62 \pm 0.15$ & $1.15 \pm 0.16$ & $0.53 \pm 0.52$ & $1.1 \pm 1.0$ \\
\hline
\end{tabular}

aRefer to Figure 12.

bSamples collection depths of 0 to $15 \mathrm{~cm}$.

c New Jersey State Plane (Feet 2900), NAD 1983 (Conus)

dRadionuclide concentrations are gross values that include background contributions.

eUncertainties represent the $95 \%$ confidence interval based on total propagated uncertainties.

fSelected as preliminary background reference sample. 


\section{REFERENCES}

Defense National Stockpile Center (DNSC). Sampling results of Columbium Tantalum Materials, records provided by DNSC staff during the ORISE June 2007 visit to the Scotia site (DNSC 1).

Defense National Stockpile Center. Sampling results of Tungsten Materials, records provided by DNSC staff during the ORISE June 2007 visit to the Scotia site (DNSC 2).

Environmental Measurements Laboratory (EML). Information retrieved on December 27, 2007 from the EML Soil Measurements Database. http://www.eml.st.dhs.gov/databases/Soils/soil data search.htm

Oak Ridge Associated Universities (ORAU). Quality Program for the Independent Environmental Assessment and Verification Program. Oak Ridge, Tennessee; November 1, 2007.

Oak Ridge Institute for Science and Education (ORISE). Preliminary Site-Specific Derived Concentration Guideline Levels for the Curtis Bay Depot, Curtis Bay, Maryland. Oak Ridge, TN; January 2006.

Oak Ridge Institute for Science and Education. Final Report-Historical Site Assessment of the Scotia Depot, Scotia, New York. Oak Ridge, TN; August 2007a.

Oak Ridge Institute for Science and Education. Survey Procedures Manual for the Independent Environmental Assessment and Verification Program. Oak Ridge, TN; August 3, 2007b.

Oak Ridge Institute for Science and Education. Laboratory Procedures Manual for the Environmental Survey and Site Assessment Program. Oak Ridge, TN; August 31, 2007c.

Oak Ridge Institute for Science and Education. Final Radiological Scoping Survey Plan for the Scotia Depot, Scotia, New York. Oak Ridge, TN; September 13, 2007d.

U.S. Nuclear Regulatory Commission (NRC). Multi-Agency Radiation Survey and Site Investigation Manual (MARSSIM), NUREG-1575; Revision 1. Washington, DC; August 2000.

U.S. Nuclear Regulatory Commission. License STC-133, Amendment No. 28;

February 21, 2007a.

U.S. Nuclear Regulatory Commission. Defense Logistics Agency, License Amendment, Control No. 138458. King of Prussia, Pennsylvania; July 9, 2007b. 
APPENDIX A

\section{MAJOR INSTRUMENTATION}




\section{APPENDIX A}

\section{MAJOR INSTRUMENTATION}

The display of a specific product is not to be construed as an endorsement of the product or its manufacturer by the author or his employer.

\section{SCANNING INSTRUMENT/DETECTOR COMBINATIONS}

\section{Alpha and Alpha plus Beta}

Ludlum Floor Monitor Model 239-1

combined with

Ludlum Ratemeter-Scaler Model 2221

coupled to

Ludlum Gas Proportional Detector Model 43-37, Physical Area: $550 \mathrm{~cm}^{2}$

(Ludlum Measurements, Inc., Sweetwater, TX)

\section{Alpha and Beta}

Ludlum Ratemeter-Scaler Model 2221

coupled to Ludlum Gas Proportional Detector Model 43-68, Physical Area: $126 \mathrm{~cm}^{2}$

(Ludlum Measurements, Inc., Sweetwater, TX)

\section{$\underline{\text { Gamma }}$}

Ludlum Pulse Ratemeter Model 12

(Ludlum Measurements, Inc., Sweetwater, TX)

coupled to

Victoreen NaI Scintillation Detector Model 489-55, Crystal: $3.2 \mathrm{~cm}$ x $3.8 \mathrm{~cm}$

(Victoreen, Cleveland, $\mathrm{OH}$ )

\section{Direct Measurement Instrument/Detector Combinations}

\section{Alpha and Beta}

Ludlum Ratemeter-Scaler Model 2221

coupled to Ludlum Gas Proportional Detector Model 43-68, Physical Area: $126 \mathrm{~cm}^{2}$ (Ludlum Measurements, Inc., Sweetwater, TX) 


\section{LABORATORY ANALYTICAL INSTRUMENTATION}

Low Background Gas Proportional Counter

Model LB-5100-W

(Tennelec/Canberra, Meriden, CT)

High Purity Extended Range Intrinsic Detector

CANBERRA/Tennelec Model No: ERVDS30-25195

(Canberra, Meriden, CT)

Used in conjunction with:

Lead Shield Model G-11

(Nuclear Lead, Oak Ridge, TN) and

Multichannel Analyzer

DEC ALPHA Workstation

(Canberra, Meriden, CT)

High Purity Extended Range Intrinsic Detector

Model No. GMX-45200-5

(AMETEK/ORTEC, Oak Ridge, TN)

used in conjunction with:

Lead Shield Model SPG-16-K8

(Nuclear Data)

Multichannel Analyzer

DEC ALPHA Workstation

(Canberra, Meriden, CT)

High-Purity Germanium Detector

Model GMX-30-P4, 30\% Eff.

(AMETEK/ORTEC, Oak Ridge, TN)

Used in conjunction with:

Lead Shield Model G-16

(Gamma Products, Palos Hills, IL) and

Multichannel Analyzer

DEC ALPHA Workstation

(Canberra, Meriden, CT) 
APPENDIX B

SURVEY AND ANALYTICAL PROCEDURES 


\section{APPENDIX B}

\section{SURVEY AND ANALYTICAL PROCEDURES}

\section{Project Health AND SAFETy}

The proposed survey and sampling procedures were evaluated to ensure that any hazards inherent to the procedures themselves were addressed in current job hazard analyses (JHAs). All survey and laboratory activities were conducted in accordance with ORISE health and safety and radiation protection procedures.

\section{Calibration AND Quality Assurance}

Calibration of all field and laboratory instrumentation was based on standards/sources, traceable to NIST.

Analytical and field survey activities were conducted in accordance with procedures from the following documents of the Oak Ridge Institute for Science and Education and Oak Ridge Associated Universities:

- $\quad$ Survey Procedures Manual (August 2007)

- $\quad$ Laboratory Procedures Manual (August 2007)

- Quality Program Manual (November 2007)

The procedures contained in these manuals were developed to meet the requirements of Department of Energy (DOE) Order 414.1C and the U.S. Nuclear Regulatory Commission Quality Assurance Manual for the Office of Nuclear Material Safety and Safeguards and contain measures to assess processes during their performance.

Quality control procedures include:

- Daily instrument background and check-source measurements to confirm that equipment operation is within acceptable statistical fluctuations.

- Participation in MAPEP, NRIP, and ITP Laboratory Quality Assurance Programs.

- Training and certification of all individuals performing procedures.

- $\quad$ Periodic internal and external audits. 
Detectors used for assessing surface activity were calibrated in accordance with ISO-7503 ${ }^{1}$ recommendations. Total alpha and beta efficiencies $\left(\boldsymbol{\varepsilon}_{\text {total }}\right)$ were determined for each instrument/detector combination and consisted of the product of the $2 \pi$ instrument efficiency $\left(\varepsilon_{i}\right)$ and surface efficiency $\left(\varepsilon_{\mathrm{s}}\right): \varepsilon_{\mathrm{total}}=\varepsilon_{\mathrm{i}} \times \varepsilon_{\mathrm{s}}$. Beta total efficiencies were determined based on a beta energy multi-point calibration, development of instrument efficiency to beta energy calibration curves, and the calculation of the weighted efficiency representing the Th-232 decay series. Included in the weighted efficiency was an empirically determined correction for disequilibrium in the decay series that results from $\mathrm{Rn}-220$ loss. A $3.8 \mathrm{mg} / \mathrm{cm}^{2}$ density thickness mylar window was used on the beta detectors to block detector response contributions from alpha radiation.

C-14, Tc-99, Tl-204, and Sr/Y-90 were selected as the calibration sources to represent the energy distribution of the detectable alpha and beta-emitters in the Th-232 decay series. The $2 \pi$ alpha interpolated instrument efficiency $\left(\varepsilon_{\mathrm{i}}\right)$ factors ranged from 0.36 to 0.67 . The thorium series total weighted alpha efficiency was 1.04 for the gas proportional detector that was used. The $2 \pi$ interpolated $\varepsilon_{\mathrm{i}}$ factors for the detectable beta-emitters ranged from 0.21 to 0.62 for the gas proportional detector. ISO-7503 recommends an $\varepsilon_{\mathrm{s}}$ of 0.25 for alpha emitters and also beta emitters with a maximum energy of less than $0.4 \mathrm{MeV}$ and an $\varepsilon_{\mathrm{s}}$ of 0.5 for maximum beta energies greater than $0.4 \mathrm{MeV}$. The total weighted beta efficiency for the beta detector was 0.43 .

\section{SuRVEy Procedures}

\section{$\underline{\text { Surface Scans }}$}

Structural surface scans were performed by passing the detectors slowly over the surface; while maintaining the distance between the detector and the surface at a minimum. Building surfaces were scanned using either a floor monitor or small area $\left(126 \mathrm{~cm}^{2}\right)$ hand-held gas proportional detectors. A $\mathrm{NaI}$ scintillation detector was used to scan for elevated gamma radiation throughout the buildings and the exterior grounds. Identification of elevated radiation levels was based on increases in the audible signal from the recording and/or indicating instrument.

${ }^{1}$ International Standard. ISO 7503-1, Evaluation of Surface Contamination - Part 1: Beta-emitters (maximum beta energy greater than $0.15 \mathrm{MeV}$ ) and alpha-emitters. August 1, 1988. 
Beta surface scan minimum detectable concentrations (MDCs) were estimated using the calculational approach described in NUREG-1507. ${ }^{2}$ The scan MDC is a function of many variables, including the background level. Additional parameters selected for the calculation of scan MDCs included a two-second observation interval, a specified level of performance at the first scanning stage of $95 \%$ true positive rate and $25 \%$ false positive rate, which yields a $d$ 'value of 2.32 (NUREG-1507, Table 6.1), and a surveyor efficiency of 0.5. The scanning instrument total efficiency $\left(\varepsilon_{\text {total }}\right)$ for the hand-held gas proportional detectors was approximately 0.40 .

The unshielded construction material-specific beta background levels ranged from 213 to $383 \mathrm{cpm}$ for the gas proportional detector. To illustrate an example for a hand-held gas proportional detector using a concrete background of $383 \mathrm{cpm}$, the minimum detectable count rate (MDCR) and scan MDC can be calculated as follows:

$$
\begin{aligned}
& \mathrm{b}_{\mathrm{i}}=(383 \mathrm{cpm})(2 \mathrm{~s})(1 \mathrm{~min} / 60 \mathrm{~s})=12.8 \text { counts, } \\
& \operatorname{MDCR}=(2.32)(12.8 \mathrm{counts})^{1 / 2}[(60 \mathrm{~s} / \mathrm{min}) /(2 \mathrm{~s})]=249 \mathrm{cpm}, \\
& \operatorname{MDCR}_{\text {surveyor }}=249 /(0.5)^{1 / 2}=352 \mathrm{cpm}
\end{aligned}
$$

The scan MDC is calculated using the weighted total efficiency of 0.43 .

$$
\text { ScanMDC }=\frac{M D C R_{\text {surveyor }}}{\left(\varepsilon_{s}\right)\left(\varepsilon_{i}\right)} \mathrm{dpm} / 100 \mathrm{~cm}^{2}
$$

For the given background, the estimated scan MDC was $820 \mathrm{dpm} / 100 \mathrm{~cm}^{2}$ for the hand-held gas proportional detector.

The scan MDC for the NaI scintillation detector for Th-232 in soil was $2.8 \mathrm{pCi} / \mathrm{g}$ as provided in NUREG-1507.

\section{Surface Activity Measurements}

Measurements of total alpha and beta surface activity levels were performed using hand-held gas proportional detectors coupled to portable ratemeter-scalers. Count rates (cpm), which were integrated over one minute with the detector held in a static position, were converted to activity

${ }^{2}$ NUREG-1507. Minimum Detectable Concentrations With Typical Radiation Survey Instruments for Various Contaminants and Field Conditions. US Nuclear Regulatory Commission. Washington, DC; June 1998. 
levels $\left(\mathrm{dpm} / 100 \mathrm{~cm}^{2}\right)$ by dividing the count rate by the total static efficiency $\left(\varepsilon_{\mathrm{i}} \times \varepsilon_{\mathrm{s}}\right)$ and correcting for the physical area of the detector. Construction material-specific background corrections were made for each surface type encountered for determining net count rates. Ten measurements were performed for each surface type to determine the construction material-specific background. Background measurements were performed in Building 23 as recommended by site employees based on historical use. To account for the ambient gamma background, unshielded and shielded measurements were performed at each location. A 3/8-inch Plexiglas shield was used to determine the gamma count rate associated with the unshielded count rates. Surface activity was calculated by determining the net count rate, subtracting the shielded measurement from the unshielded measurement, then correcting for total efficiency and detector area size.

Surface activity measurements were performed on poured concrete, concrete block, metal, and wood. The static beta MDCs ranged from 130 to $170 \mathrm{dpm} / 100 \mathrm{~cm}^{2}$ for the gas proportional detector. The physical surface area assessed by the gas proportional detector used was $126 \mathrm{~cm}^{2}$.

\section{$\underline{\text { Removable Activity Measurements }}$}

Smear samples for removable gross alpha and gross beta contamination were obtained from direct measurement locations. Removable activity samples were collected using numbered filter paper disks, $47 \mathrm{~mm}$ in diameter. Moderate pressure was applied to the smear and approximately $100 \mathrm{~cm}^{2}$ of the surface was wiped. Smears were placed in labeled envelopes with the location and other pertinent information recorded.

\section{RADiOLOGICAL ANALYSIS}

\section{Gross Alpha/Beta}

Smears were counted on a low-background gas proportional system for gross alpha and beta activity. The MDCs of the procedure were $9 \mathrm{dpm} / 100 \mathrm{~cm}^{2}$ and $15 \mathrm{dpm} / 100 \mathrm{~cm}^{2}$ for a 2 -minute count time for gross alpha and gross beta, respectively.

\section{Gamma Spectroscopy}

Soil samples were dried, mixed, crushed, and/or homogenized as necessary, and a portion sealed in a 0.5-liter Marinelli beaker or other appropriate container. The quantity placed in the beaker was 
chosen to reproduce the calibrated counting geometry. Net material weights were determined and the samples counted using intrinsic germanium detectors coupled to a pulse height analyzer system. Background and Compton stripping, peak search, peak identification, and concentration calculations were performed using the computer capabilities inherent in the analyzer system. All total absorption peaks (TAP) associated with the radionuclides of concern were reviewed for consistency of activity. TAPs used for determining the activities of radionuclides of concern and the typical associated MDCs for a one-hour count time were:

\begin{tabular}{|c|c|c|}
\hline \hline Radionuclide & TAP $(\mathrm{MeV})$ & MDC $(\mathrm{pCi} / \mathrm{g})$ \\
\hline \hline Th-232 & 0.911 from Ac-228* & 0.11 \\
\hline $\mathrm{U}-238$ & 0.063 from Th-234* & 0.70 \\
\hline
\end{tabular}

*Secular equilibrium assumed.

Spectra were also reviewed for other identifiable TAPs.

\section{DETECTION Limits}

Detection limits, referred to as minimum detectable concentration (MDC), were based on 3 plus 4.65 times the standard deviation of the background count $\left[3+\left(4.65(\mathrm{BKG})^{1 / 2}\right)\right]$. Because of variations in background levels, measurement efficiencies, and contributions from other radionuclides in samples, the detection limits differ from sample to sample and instrument to instrument. 